\title{
Stochastic Nonlinear Ground Response Analysis Considering Existing Boreholes Locations by the Geostatistical Method
}

\author{
A.H. Amjadi \\ Shiraz University of Technology \\ Ali johari ( $\nabla$ johari@sutech.ac.ir) \\ Shiraz University of Technology https://orcid.org/0000-0002-5988-6964
}

\section{Research Article}

Keywords: Ground response, Nonlinear soil behavior, Extended Masing rules, Stochastic analysis, Geostatistical method, Non-stationary random field

Posted Date: July 27th, 2021

DOI: https://doi.org/10.21203/rs.3.rs-732056/v1

License: (c) (i) This work is licensed under a Creative Commons Attribution 4.0 International License. Read Full License

Version of Record: A version of this preprint was published at Bulletin of Earthquake Engineering on January 25th, 2022. See the published version at https://doi.org/10.1007/s10518-022-01322-1. 


\title{
Stochastic nonlinear ground response analysis considering existing boreholes locations by the geostatistical method
}

\author{
A.H. Amjadi ${ }^{1}$, A. Johari ${ }^{1 *}$ \\ 1- Department of Civil and Environmental Engineering, Shiraz University of Technology, Shiraz, Iran \\ johari@sutech.ac.ir*
}

\begin{abstract}
The field and laboratory evidence of nonlinear soil behavior, even at small strains, emphasizes the importance of employing nonlinear methods in seismic ground response analysis. Additionally, determination of dynamic characteristics of soil layers always includes some degree of uncertainty. Most of previous stochastic studies of ground response analysis have focused only on uncertainties of soil parameters, and the effect of soil sample location has been mostly ignored. This study attempts to couple nonlinear time-domain ground response analysis with uncertainty of soil parameters considering existing boreholes' location through a geostatistical method using a program written in MATLAB. To evaluate the efficiency of the proposed method, stochastic seismic ground responses at construction location were compared with those of the non-stationary random field method through real site data. The results demonstrate that applying the boreholes' location significantly affects not only the ground responses but also their Coefficient Of Variation (COV). Furthermore, the mean value of the seismic responses is affected more considerably by the values of soil parameters at the vicinity of the construction location. It is also inferred that considering boreholes' location may reduce the COV of the seismic responses. Among the surface responses in the studied site, the values of Peak Ground Displacement (PGD) and Peak Ground Acceleration (PGA) reflect the highest and lowest dispersion due to uncertainties of soil properties through both non-stationary random field and geostatistical methods.
\end{abstract}

Keywords: Ground response, Nonlinear soil behavior, Extended Masing rules, Stochastic analysis, Geostatistical method, Non-stationary random field

\section{Introduction}

Prediction of ground response from an earthquake is a fundamental step to estimate the possible damages of structures. The amplitude of earthquake motions at the bedrock level can be drastically modified as seismic waves are transmitted through a soil deposit. Some historical earthquake events have demonstrated the effects of soil deposits on earthquake ground motions. In recent years, several major studies have been performed to study the nature of earthquakes occurrence, the associated released energy, and the effects of site parameters.

Ground response analysis can be performed based on different considerations of problem geometry and seismic soil behavior models. One-dimensional (1-D) ground response analyses are the most commonly used technique because of their simplicity and reasonable assumptions, including horizontal layering of soil deposits and SH-waves propagation [1]. Ground response analysis of horizontally-layered soil deposits can be conducted by employing various methods which are categorized into Frequency-Domain (FD), including the equivalent-linear , (e.g., SHAKE [2]), Time-Domain (TD) [3-5], Hybrid Frequency Time Domain (HFTD) [6] methods.

Frequency-domain methods are the most widely used to estimate seismic site effects due to their simplicity. However, these methods are unable to consider true nonlinear soil models, but only linear elastic models. Since the nonlinearity of soil behavior is well known, the linear approach was modified to the equivalent-linear method by Schnabel et al. [2]. Their efforts led 
to the development of an equivalent-linear program, SHAKE. Jishnu et al. [7] used SHAKE to determine the surface response and amplification ground response analysis of a site in India. Garini et al. [8] investigated soil amplification in three sites during the Tokachi-Oki earthquake using the SHAKE and two nonlinear programs. Torabi and Rayhani [9] conducted a number of site response analyses in both nonlinear time-domain and equivalent-linear frequency-domain methods for a site in Canada. The results suggested that the nonlinear analysis would provide a more reliable prediction of ground motion at the natural site period. Kim and Hashash [10] performed one-dimensional ground response analyses on Kiban-Kyoshin network (KiK-net) recorded data of the 2011 Tohoku earthquake to evaluate the applicability of equivalent-linear and nonlinear site response methods. The results revealed that the differences between the where the estimated maximum strains are larger than $0.3 \%$ are more significant, and equivalent-linear site response models mispredicted the site amplifications. Yee et al. [11] studied free-field downhole recorded ground motions from the 2007 Niigata-ken Chuetsu-oki earthquake at the site of a nuclear power plant. Their results indicated that the nonlinear site response provides a better representation of the high-frequency energy content in the initial parts of the ground motion relative to equivalent-linear analysis.

Although the equivalent-linear approach provides reasonable results when the ground motions are not significant, it may mispredict the ground responses due to severe seismic excitations [12]. An alternative approach is to analyze the actual nonlinear ground response. For the first time, Masing [13] presented nonlinear hysteretic behavior by using stress-strain relations, which is named the Masing rules. Pyke [14] and Vucetic [15] proposed the extended Masing rules, which define unloading-reloading-behavior under general cyclic loading. As a result of this progress, a nonlinear solution of the shear wave propagation was carried out by a number of researchers. Using the hyperbolic model, Lee and Finn [16] developed a 1-D site response analysis program. Matasovic and Vucetic [3] modified the hyperbolic model and coupled it with extended Masing rules to better simulation of soil hysteretic behavior. Cyclic soil behavior also can be simulated by plasticity constitutive models. For example, Constantopoulos et al. [17] obtained the ground response during an earthquake by Ramberg-Osgood [18] soli model. Joyner and Chen [19] used the Iwan model [20] for presenting a method for calculating the nonlinear seismic response of a profile with horizontal soil layers. Borja et al. [21] utilized a bounding surface plasticity model to simulate cyclic soil behavior response at a site in Taiwan. Hashash and Park [22] developed a new nonlinear 1-D site response analysis model, which could consider the effect of large confining pressures. Phillips and Hashash [23] presented two new formulations of soil damping for small and large strains. Assimaki et al. [24] proposed a set of criteria for quantification of nonlinear behavior susceptibility using data from three sites in the Los Angeles basin. The results indicated that nonlinear analyses are necessary at soft sites when the PGA of input acceleration is greater than 0.2 g. In a comprehensive study, Kaklamanos et al. [25] selected a set of 191 ground motions records at six sites in the KiK-net. Then the approximate applicable thresholds of different site response analyses methods, including linear, equivalent-linear, and nonlinear analyses, were proposed. Angina et al. [26] carried out a study to obtain the free-field seismic response of the site of Pisa tower. The results indicated that the response spectra obtained with the nonlinear code ONDA [4] and corresponding amplification factors were significantly lower than those 
computed using the equivalent-linear codes. It is worth mentioning that among the available 1D ground response analysis codes, only ONDA [4] and DEEPSOIL [5] account for soil strength.

Due to the inherent uncertainty in determining soil parameters, it is necessary to carry out non-deterministic analyses. During the past few years, there has been a considerable increase in recent researches dedicated to this topic. Rahman and Yeh [27] coupled Monte Carlo Simulation (MCS) with the Finite Element Method (FEM) to study the uncertainties of soil parameters in frequency-domain analysis. Wang and Hao [28] assessed the influence of random variations of soil properties on the site amplification in the frequency-domain by employing Point Estimate Method (PEM) [29]. Nour et al. [30] combined MCS with the FEM to simulate uncertainties of the soil profile in seismic response analysis. Bazzurro and Cornell [31] presented a statistical ground response study based on the nonlinear finite element program, which was presented by Li et al. [32]. Andrade and Borja [33] performed a stochasticdeterministic analysis of site response using two computer codes (SHAKE, SPECTRA). Thompson et al. [34] estimated the spectral amplifications from seismic properties using the square root of the impedance method. In their study, the geostatistical approaches were used to increase the accuracy of the results. Rota et al. [35] developed a procedure for estimating the stochastic site amplification of a case study in central Italy. Johari and Momeni [36] proposed a procedure for estimating the stochastic site amplification of soil deposits with uncertain properties by combining the non-recursive algorithm of the HFTD site response approach and MCS. The influence of soil uncertainty in the shear-wave velocity, density, thickness of profile, and soil properties was studied. The results of the sensitivity analysis showed that the damping ratio is the most influential parameter in enhancing the surface peak ground acceleration. Berkane et al. [37] investigated the effects of the soil properties heterogeneity due to their natural randomness on the spatial variation of the response spectra at different sites. Their results showed that soil properties' randomness significantly affects the amplitudes of the response spectra. Johari et al. [38] employed the sequential compounding method through the frequency-domain site response analysis to propose a method for conducting system reliability analysis of the surface PGA by considering soil layers cross-correlation. Their findings in the studied site demonetrated the reasonable accuracy of the proposed method for calculating the reliability indices of ground surface PGAs.

The common feature of the mentioned stochastic ground response analysis study is the use of linear or equivalent-linear methods and consideration of variability in soil parameters using the random variables method, while it is expected that the use of nonlinear time-domain methods shall be more capable of considering the real behavior of the soil. On the other hand, the random variables method does not have the ability to consider the existing boreholes' location. Therefore, this study aims to overcome the mentioned limitations and develop a method for combining the nonlinear behavior of soil parameters and their uncertainties by considering the borehole location effects through the geostatistical method for a real site. In order to evaluate the efficiency of the geostatistical method for considering the spatial variability of soil parameters, the results of this method were compared and discussed with that of the non-stationary random field method. The uncertainty influence of such soil properties as Plastic Index (PI), shear wave velocity $\left(\mathrm{V}_{S}\right)$, and unit weight $(\gamma)$ are assessed through MCS. The mean and $\mathrm{COV}$ of the ground motion parameters and the amplification factor for the non- 
1 stationary random field and geostatistical-based stochastic analysis through the nonlinear method are determined and compared using a program prepared in MATLAB.

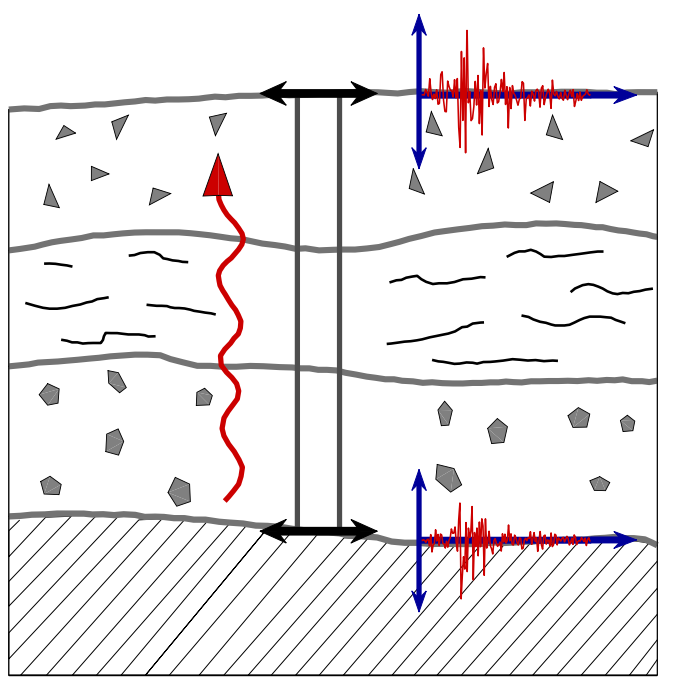

Fig. 1. Graphical description of 1-D site response

\section{Nonlinear site response analysis} shown in Fig. 2.

\section{analysis}
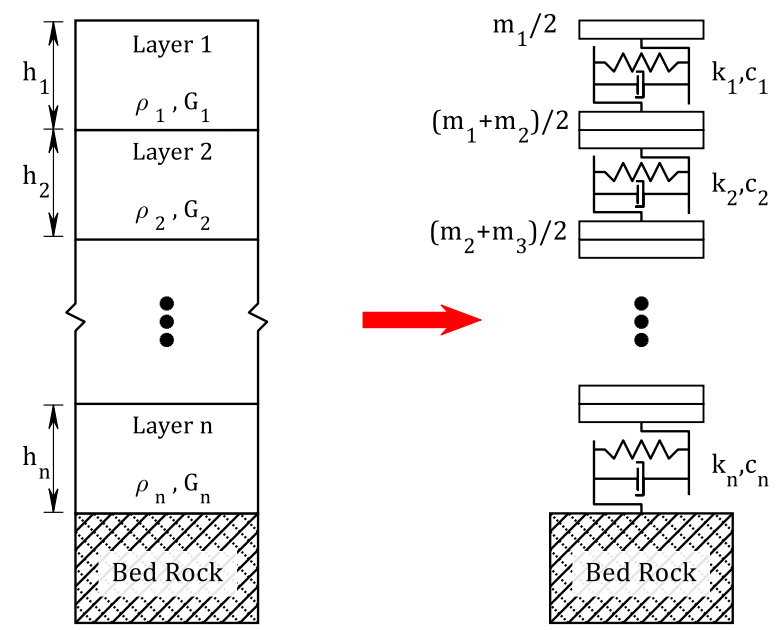

Fig. 2. schematic MDOF system with rigid base

The main purpose of site response analysis is to obtain the wave amplitude at the top of soil layers based on bedrock with an incoming shear wave motion generated by an earthquake that propagates vertically upward, as shown in Fig. 1. The soil deposit is assumed to be made of several homogeneous horizontal layers with an infinite extent. Ground motions are considered to be generated horizontally at the soil-bedrock interface. In 1-D nonlinear site response analyses, the soil column is idealized as Multi Degrees of Freedom (MDOF) lumped mass system, in which each soil layer is depicted by a corresponding mass, nonlinear spring, and dashpot, as

The real nonlinear behavior can be modeled via a time-domain analysis by the use of direct numerical integration (e.g., the central difference method, Newmark $\beta$ method [39], and Wilson $\theta$ methods [40]) of the equation of motion (Eq. (1)) for each time increment.

$[M]\{\ddot{u}\}+[C]\{\dot{u}\}+[K]\{u\}=-[M]\{I\}\left\{\ddot{u}_{g}\right\}$

where $[M]$ is the mass matrix, $[C]$ is the viscous damping matrix, $[K]$ is the stiffness matrix, $\{\ddot{u}\}$ is the vector of nodal relative accelerations, $\{\dot{u}\}$ is the vector of nodal relative velocities, $\{u\}$ is the vector of nodal relative displacements, $\{l\}$ is the unit vector, and $\left\{\ddot{u}_{g}\right\}$ is the acceleration at the base of the soil column. In the 1-D nonlinear site response analyses, the coefficient matrices of the equation of motion $[M],[C]$, and $[K]$ are described as follows:

The mass matrix $M$ is a diagonal matrix formed by lumping half of the mass of each two sequential layers at their common boundary, as illustrated in Fig. 2. Note that the mass of layer " $i$ " is found by: 
$m_{i}=\rho_{i} \times h_{i}$

where $\rho_{i}$ and $h_{i}$ are the density and the height of layer $i$, respectively.

The stiffness matrix K should be updated at each time step to account for soil nonlinearity. According to the 1-D wave propagation assumption, the stiffness matrix can be defined using a simple shear model as follows:

$k_{i}=G_{i} / h_{i}$

where $G_{i}$ is the shear modulus of layer $i$, that is obtained through nonlinear shear modulus models at each time step.

In a nonlinear analysis, soil damping is obtained from hysteretic loading-unloading cycles. The use of the viscous damping matrix $[C]$ in the Eq. (1) is necessary to avoid unrealistic high frequencies resonance at very small strains. The viscous damping matrix formulation proposed by Rayleigh and Lindsay [41], known as Rayleigh damping, is defined as follows:

$[C]=\alpha[M]+\beta[K]$

The scalar values of $\alpha$ and $\beta$ are calculated from two natural frequencies corresponding to natural modes $m$ and $n$, as follows:

$\left[\begin{array}{l}\xi_{m} \\ \xi_{n}\end{array}\right]=\frac{1}{4 \pi}\left[\begin{array}{ll}1 / f_{m} & f_{m} \\ 1 / f_{n} & f_{n}\end{array}\right]\left\{\begin{array}{l}\alpha \\ \beta\end{array}\right\}$

where $\xi_{m}$ and $\xi_{n}$ are the damping ratios for the target frequencies $f_{m}$ and $f_{n}$.

Based on Stewart et al. [42] recommendation, the $f_{m}$ and $f_{n}$ frequencies can be the natural frequencies corresponding to the first and third natural modes of the soil profile and the $\xi_{m}$ and $\xi_{n}$ can be set equal.

\section{Nonlinear modified hyperbolic models}

Several empirical models have been proposed in the literature for estimating shear modulus reduction and damping curves. Among important contributions are the models of Vucetic and Dobry [43], Darendeli [44], Menq [45], Kishida et al. [46], and Yang and Woods [47]. The empirical models, such as Darendeli [44], Menq [45], and Kishida et al. [46] are utilized to simulate the dynamic soil parameters in the site response analyses when no dynamic laboratory tests were conducted. A nonlinear simple-shear model is based on the following principles:

- A basic formula for determining the stress-strain path at initial loading (backbone curve)

- A series of criteria (rules) for determining the unloading and reloading soil behavior

In this paper, the Darendeli [44] modified hyperbolic model was implemented in modeling the backbone curve and the extended Masing rule $[14,15]$ was used for governing the unloading and reloading behavior of subsequent cycles. Additionally, in order to prevent the overestimation of damping during hysteretic cycles in the Darendeli model [44], the second Masing rule was modified in accordance with Pyke [14] proposed hypothesis. 


\subsection{Darendeli nonlinear model}

Darendeli [44] proposed a model to estimate shear modulus reduction and damping curves from a soil test database using a first-order, second-moment Bayesian method. The model is based on the simple hyperbolic model proposed by Kondner and Zelasko [48] and Hardin and Drnevich [49], but added a curvature coefficient, ' $a=0.919$ ', as follows:

$$
\tau=F_{b b}(\gamma)=\frac{G_{\max } \gamma}{1+\left(\gamma / \gamma_{r}\right)^{a}}
$$

where $\gamma_{r}$, is the shear strain when $G / G_{\max }$ equals 0.5 , which can be obtained by the following equation:

$$
\gamma_{r}=\left(0.0352+0.001 \times P I \times O C R^{0.3246}\right)\left(\sigma_{m}^{\prime}\right)^{0.3483}
$$

where $P I$ is plasticity index, $O C R$ is the over-consolidation ratio, and $\sigma_{m}^{\prime}$ is the mean effective confining pressure.

Based on Darendeli assumption, total damping is formed from two main parts, namely, small strain damping $\left(D_{\min }\right)$ caused by internal friction and material viscosity and the damping corresponding to soil nonlinearity or hysteresis behavior (D $D_{\text {Masing }}$ [ [44]:

$$
D=F \times D_{\text {Masin } g}+D_{\text {min }}
$$

where $D$ is total damping, and $F$ is a reduction factor. $D_{\text {Masing }}$ is proportional to the ratio of the dissipated energy to stored strain energy in one complete cycle of motion. $\mathrm{D}_{\min }$ is calculated by the following equation[44]:

$$
D_{\text {min }}(\%)=\left(\sigma_{0}^{\prime}\right)^{-0.2889}\left(0.8005+0.0129 P I \times O C R^{-0.1069}\right)(1+0.2919 \ln (f))
$$

where $f$ is loading frequency.

\subsection{Extended Masing rules}

The stress-strain relationship for initial loading is named the backbone curve. The Masing rules [13] and extended Masing rules [14, 15] describe unloading-reloading behavior under general cyclic loading conditions, as shown in Fig. 3. The Masing and extended Masing rules are explained as follows [22]:

1) The stress-strain curve follows the backbone curve for initial loading.

2) The unloading and reloading curves have the same shape as the backbone curve but enlarged by a factor of "C" with the origin shifted to the reversal point $\left(\gamma_{\text {rev }} \tau_{\text {rev }}\right)$.

$$
\frac{\tau-\tau_{r e v}}{C}=F_{b b}\left(\frac{\gamma-\gamma_{r e v}}{C}\right)
$$


1 where the " $\mathrm{C}$ " is the scale factor of the stress-strain relationship between the initial loading and the unloading and reloading cycles. The " $\mathrm{C}$ " factor can be considered as a constant coefficient equal to 2. An alternative way suggested by Pyke [14] is to take it as a function of stress level:

$$
C=1-\frac{\tau_{\text {rev }}}{\left( \pm \tau_{\text {ult }}\right)}
$$

4 where the $\tau_{\text {ult }}$ is the ultimate soil stress $\left(\tau_{\text {ult }}=G_{\max } \gamma_{r}\right)$, the " \pm " symbol is equal to " + " when the

5 shear strain increment $(d \gamma)$ is positive and is equal to "-" when the shear strain increment is negative.

3) When the unloading or reloading curve exceeds the maximum past strain and intersects the backbone curve, the stress-strain path follows that of the backbone curve until the next reversal point.

4) When the unloading or reloading curve intersects the curve from the previous cycle, then the stress-strain curve follows the path of the previous cycle.

As mentioned before, in this study, instead of using a constant factor in the second Masing rule, the Pyke [14] hypothesis is implemented in the MATLAB code

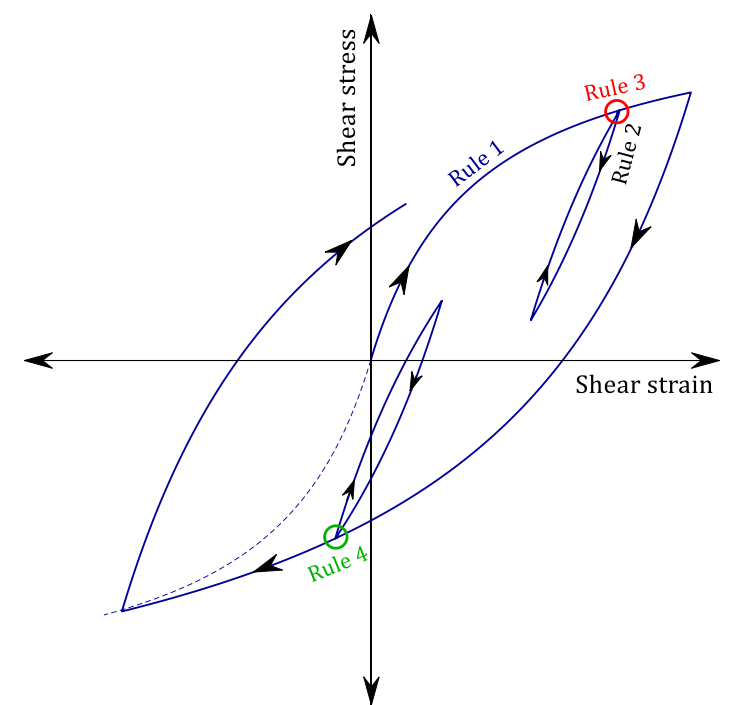

Fig. 3. Schematic description of extended Masing rules

\subsection{Error reduction process in nonlinear analysis}

The procedure of solving a nonlinear problem by a series of linear estimations with a constant time step can lead to unacceptably inaccurate results. The two major causes of errors are utilizing tangent stiffness instead of the secant stiffness and employing a constant time step, which causes a delay in detecting reversal points in the force-deformation relationship [50].

In order to reduce these errors, it is necessary to use iterative methods such as the Newton-Raphson. The Newton-Raphson iteration method is divided into two main categories, the regular and the modified Newton-Raphson. The difference between these two methods is in the basis point for calculating the stiffness matrix. In the regular Newton-Raphson, the stiffness is updated at every iteration. While in the modified Newton-Raphson method, the stiffness is once evaluated at the beginning of the iterations. All the consecutive iterations are calculated with the same stiffness, which reduces the computational cost and leads to faster convergence. 
In the present study, the modified Newton-Raphson method is implemented in the nonlinear analysis to reduce the numerical errors.

\section{Implementing the soil uncertainties in the ground response analysis}

The variable nature of soil properties that affect the ground responses indicates the necessity of considering the stochastic aspect of input parameters. Randomizing the input parameters allows to investigate the way uncertainty of the latter is mapped onto the uncertainty of outputs, which here are ground responses. This process will improve engineering judgment. The first step in stochastic analysis is selecting random variables and determining their characteristics, including the mean, standard deviation, and the statistical distribution type $[51,52]$.

Soil properties variation is one of the main sources of uncertainty in the ground response problem that can alter the results. The common methods for considering the soil parameters variability are the random variable, stationary random field, non-stationary random field, and geostatistics. The random variable method is usually utilized when it aims to evaluate the uncertainty of an output parameter, which is defined as a function of several input parameters with known uncertainty. This method does not affect the location of the recorded data. The stationary random field method creates a variable range of parameters in a domain by considering a constant mean and standard deviation for the whole field. Although this method has been widely applied in geotechnical studies, it cannot implement the depth dependency of the mean and variance soil properties [53]. Therefore, the random variable and stationary random field method can not predict reasonable soil spatial variability in stochastic problems such as site response analysis. The site response analysis is significantly affected by the natural trend in soil parameters (i.e., the increasing trend of shear wave velocity with depth). Hence, the non-stationary random field and geostatistical method are capable of considering natural depthdependent trend in soil parameters, are employed in this study and explained in the following.

\subsection{Non-stationary random field}

Site investigation data revealed the depth dependency of soil properties in natural fields [54]. The non-stationary random field describes the depth-dependent nature of the soil parameters. Li et al. [53] proposed a non-stationary random field model for simulating shear strength variability. In the present study, the same procedure was utilized to model the soil parameters' spatial variability. In this way, nonlinear regression was conducted on the field data to find the best fit of the parameters depth-dependent trend. Then the non-stationary random fields were generated base on the obtained trends.

\subsection{Geostatistical estimation}

Geostatistics, initially developed in the mining industry, is now being applied widely in geotechnical projects $[34,55]$. The most common geostatistical estimation technique is the 
ordinary Kriging method, which is based on the BLUE algorithm (Best Linear Unbiased Estimator). It is used as a univariate (single regionalized variable) tool to perform spatial interpolation between known borehole data. Furthermore, Kriging allows estimating a spatially correlated soil property at a point where no measurements are available from measurements at neighboring points. This capability of the geostatistical method can be very useful, especially when project conditions and technical limitations do not allow sampling of some desirable points. On the other hand, multivariate geostatistical analysis refers to the study of two or more co-regionalized variables. The Cokriging method can be applied to this kind of analysis in order to take the complicated cross-correlation structures into consideration [55]. In this paper, the Kriging method was employed to determine the uncertainties of the dynamic soil parameters at construction location.

\section{The procedure of stochastic analysis}

In the previous sections, the procedure of deterministic nonlinear site response analysis was described. In this section, the process of applying uncertainties of the soil parameters in the nonlinear ground response analysis is expressed.

Generally, this procedure can be divided into three main parts. The first part is the ground motion process, which includes the definition of an input acceleration, the baseline correction, and the sub-dividing of that. The second part is the random soil profile process in which, at first, the layers' soil properties are obtained by downhole and laboratory tests. Then two different methods, including non-stationary random field and geostatistical estimation, are implemented for considering the spatial variability of soil parameters. In the non-stationary random field model, estimations are based on depth-dependent trends, obtained by conducting nonlinear fitting on the average values of boreholes' data. In contrast, the geostatistical method is based on Kriging estimation to apply the boreholes' location on determining the mean and standard deviation of the dynamic soil parameters. In the next step, using the non-stationary random field and geostatistical method, "N" different random soil profiles were generated. In the third part, the nonlinear ground response analysis is carried out for each simulation. Finally, through the MCS, the statistical distribution of outputs, including Peak Ground Displacement (PGD), Peak Ground Acceleration (PGA), acceleration response spectra $\left(\mathrm{S}_{\mathrm{a}}\right)$, and the amplification factor of the site, are calculated. Fig. 4 shows the flowchart of the proposed stochastic procedure for considering the existing boreholes' location. 


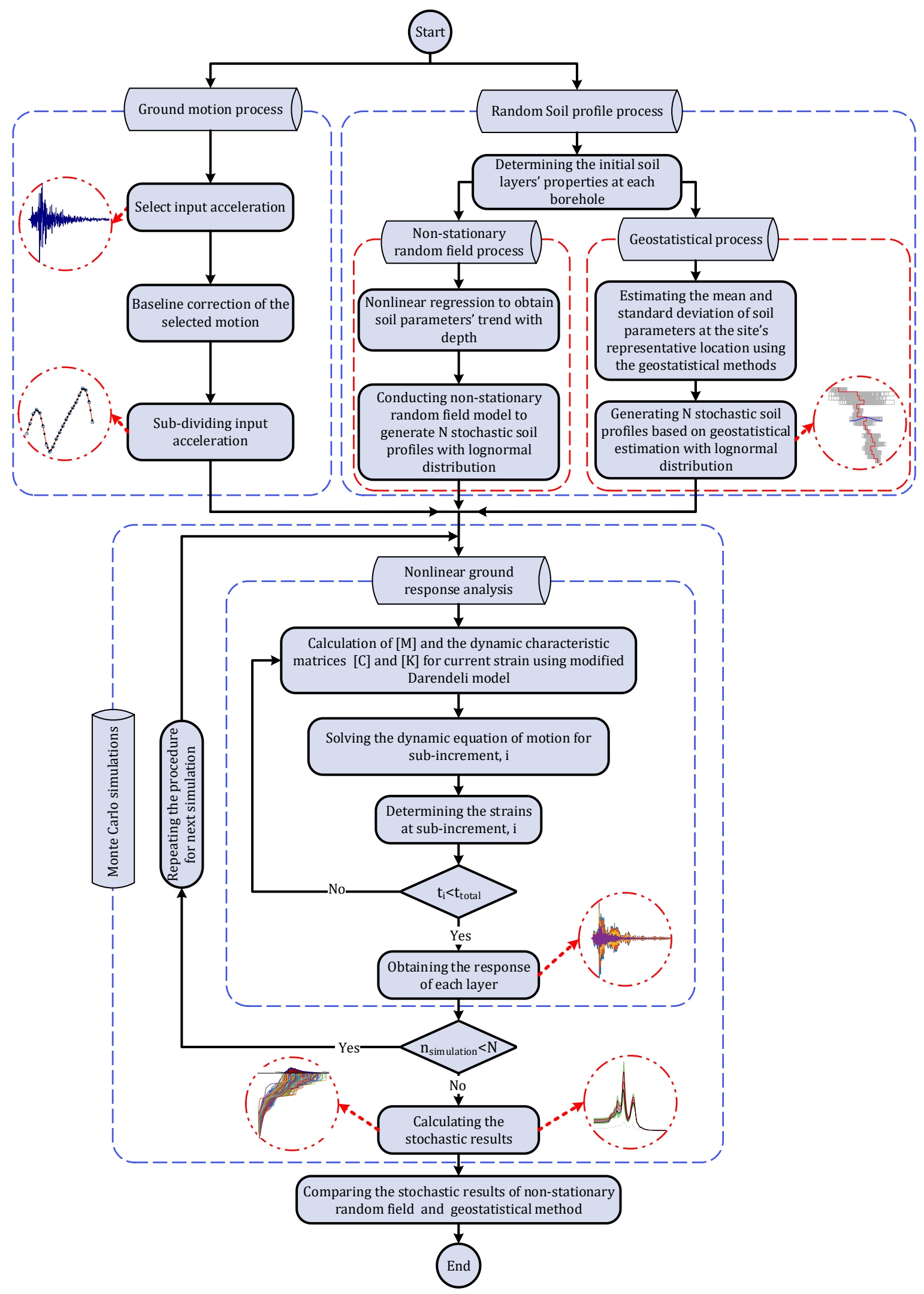

Fig. 4. Flowchart of the proposed method for the nonlinear stochastic ground response analysis 


\section{Computer program}

In this study, a computer program has been developed in MATLAB for stochastic nonlinear time-domain ground response analysis based on two different methods, including non-stationary random field and geostatistical estimation. The major ability of the program is as follows:

- Signal processing on strong-motion data to obtain suitable input acceleration (baseline correction and sub-dividing input acceleration)

- Calculation of the initial dynamic soil parameters of layers from imported profile data

- Modeling the soil layers spatial variability through the non-stationary random field model and geostatistical method

- Considering the nonlinear behavior of soil profile by the modified Darendeli model [44]

- Solving the equation of motion by the Newmark $\beta$ method coupled with the NewtonRaphson procedure by controllable accuracy and convergence

- Calculation of stochastic peak ground motion parameters, $S_{a}$, and the amplification factor for each layer by MCS

\section{Geotechnical and geophysical parameters of the site}

To demonstrate the ability of the proposed method for considering boreholes locations effects in stochastic nonlinear site response analysis, a site with real data, which is located in Shiraz city in the Fars province of Iran, is assessed. Three boreholes with approximately $36.0 \mathrm{~m}$ depth from the ground surface were drilled to investigate the subsurface layers and soil properties.

In this project, due to technical limitations, it was not possible to dig a borehole at the construction location; therefore, ground response analyses were performed based on adjacent boreholes' data. The boreholes' arrangement and the hypothetical borehole at the construction location are presented in Fig. 5. The propagation velocity of shear waves was measured in each borehole every $2.0 \mathrm{~m}$. In addition, unit weight and plasticity index were inferred from undisturbed samples retrieved from each borehole. The results are given in Table 1. It can be seen that the soil types are mainly of fine grain size. In these tables, PI, $\gamma$, and $\mathrm{V}_{s}$ are the mean of plasticity index, unit weight, and shear wave velocity of the soil layers, respectively.

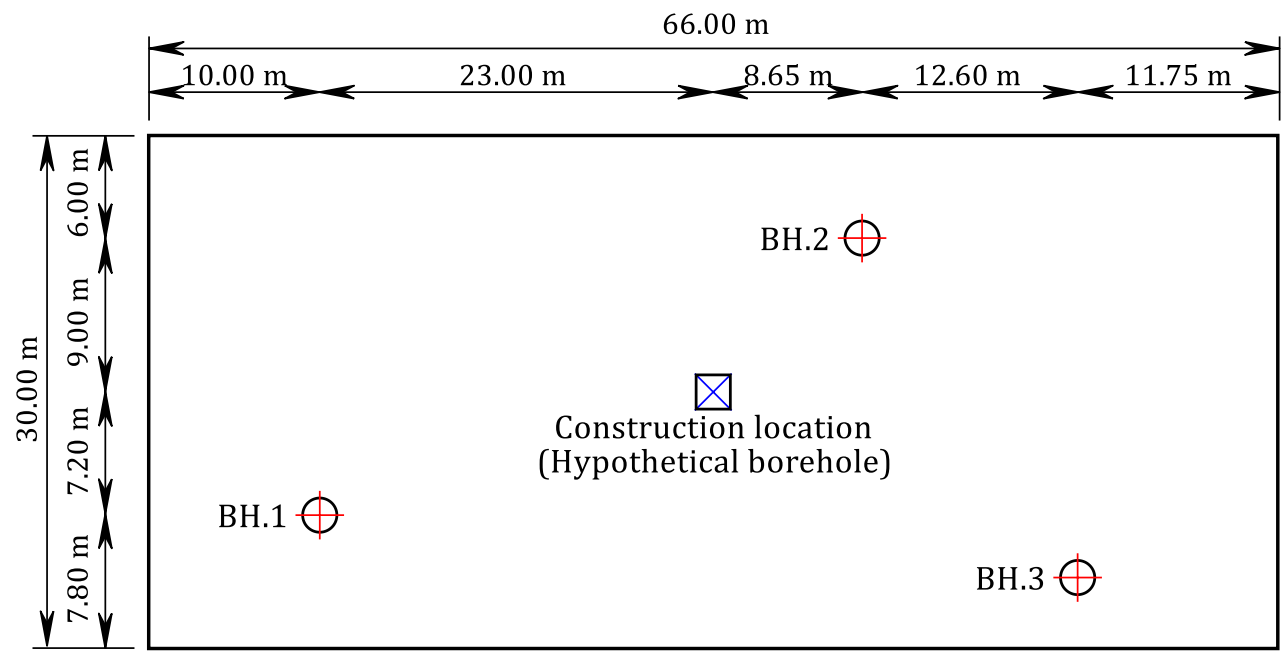


Fig. 5. The boreholes arrangement in the site plan

Table 1. Geotechnical soil properties of boreholes

\begin{tabular}{|c|c|c|c|c|c|c|c|c|c|c|c|c|c|}
\hline \multirow{2}{*}{$\begin{array}{c}\text { Layer } \\
\text { No. }\end{array}$} & \multirow{2}{*}{$\begin{array}{c}\text { Depth } \\
\text { (m) }\end{array}$} & \multicolumn{4}{|c|}{ BH.1 } & \multicolumn{4}{|c|}{ BH.2 } & \multicolumn{4}{|c|}{ BH.3 } \\
\hline & & Classification & $\begin{array}{c}\text { PI } \\
(\%)\end{array}$ & $\begin{array}{c}\gamma \\
\left(\mathrm{kN} / \mathrm{m}^{3}\right)\end{array}$ & $\begin{array}{c}\mathrm{V}_{\mathrm{s}} \\
(\mathrm{m} / \mathrm{sec})\end{array}$ & Classification & $\begin{array}{c}\text { PI } \\
(\%)\end{array}$ & $\begin{array}{c}\gamma \\
\left(\mathrm{kN} / \mathrm{m}^{3}\right.\end{array}$ & $\begin{array}{c}\mathrm{V}_{\mathrm{s}} \\
\mathrm{m} / \mathrm{sec} \text { 圆 }\end{array}$ & Classification & $\begin{array}{c}\text { PI } \\
(\%)\end{array}$ & $\begin{array}{c}\gamma \\
(\mathrm{kN} / \mathrm{m}\end{array}$ & $\begin{array}{c}\mathrm{V}_{\mathrm{s}} \\
\mathrm{m} / \mathrm{sec} \text { 圆 }\end{array}$ \\
\hline 1 & $0-2$ & CL-ML & 6.30 & 17.02 & 161.2 & CL & 7.85 & 17.31 & 184.7 & $\overline{M L}$ & 6.36 & 17. & 157.2 \\
\hline 2 & $2-4$ & CL-ML & 6.68 & 17.69 & 231.9 & CL & 7.58 & 18.09 & 263.7 & ML & 6.28 & 17.78 & 233.3 \\
\hline 3 & $4-6$ & CL-ML & 5.40 & 17.97 & 248.0 & ML & 6.34 & 18.24 & 280.6 & GM & 5.09 & 18.12 & 248.3 \\
\hline 4 & $6-8$ & CL-ML & 4.50 & 18.16 & 318.8 & SM & 5.93 & 18.53 & 328.9 & SM & 4.85 & 18.37 & 253.2 \\
\hline 5 & $8-10$ & ML & 5.14 & 18.54 & 300.1 & CL-ML & 6.28 & 18.65 & 351.5 & CL-ML & 5.30 & 18.29 & 291.0 \\
\hline 6 & $10-12$ & CL-ML & 6.32 & 18.61 & 329.9 & CL-ML & 7.61 & 18.86 & 387.4 & CL-ML & 6.82 & 18.54 & 301.3 \\
\hline 7 & $12-14$ & SM & 7.49 & 18.59 & 302.4 & CL-ML & 8.62 & 18.82 & 368.1 & CL-ML & 7.39 & 18.32 & 318.3 \\
\hline 8 & $14-16$ & CL-ML & 6.72 & 19.02 & 366.2 & SM & 8.31 & 19.24 & 459.4 & ML & 6.85 & 19.12 & 399.4 \\
\hline 9 & $16-18$ & ML & 5.89 & 19.01 & 403.0 & SM & 7.42 & 19.34 & 491.7 & ML & 6.20 & 19.13 & 408.5 \\
\hline 10 & $18-20$ & SM & 4.21 & 19.16 & 350.0 & CL-ML & 6.25 & 19.37 & 463.6 & SM & 4.01 & 19.24 & 410.2 \\
\hline 11 & $20-22$ & CL-ML & 4.77 & 19.29 & 396.1 & ML & 5.56 & 19.57 & 449.0 & CL-ML & 4.26 & 19.34 & 382.2 \\
\hline 12 & $22-24$ & CL-ML & 5.01 & 19.35 & 423.8 & CL-ML & 5.88 & 19.58 & 519.9 & CL-ML & 4.84 & 19.37 & 440.1 \\
\hline 13 & $24-26$ & CL-ML & 4.73 & 19.78 & 483.0 & CL-ML & 5.47 & 19.98 & 570.5 & CL-ML & 5.05 & 19.70 & 458.9 \\
\hline 14 & $26-28$ & CL-ML & 4.81 & 19.78 & 468.4 & ML & 5.52 & 20.19 & 660.0 & CL-ML & 4.83 & 20.02 & 530.9 \\
\hline 15 & $28-30$ & SM & 4.49 & 19.85 & 477.7 & CL-ML & 5.30 & 20.13 & 649.8 & ML & 4.13 & 19.89 & 522.6 \\
\hline 16 & $30-32$ & SM & 4.50 & 20.08 & 519.2 & SM & 5.30 & 20.21 & 670.7 & SM & 4.70 & 19.94 & 539.5 \\
\hline 17 & $32-34$ & GM & 3.96 & 20.13 & 608.1 & GM & 4.70 & 20.35 & 694.1 & GM & 4.11 & 20.04 & 623.3 \\
\hline 18 & $34-36$ & GM & 3.26 & 20.24 & 715.2 & GM & 3.88 & 20.48 & 768.2 & GM & 3.32 & 20.27 & 725.8 \\
\hline
\end{tabular}

Although the 1-D ground response analysis is only appropriate for laterally homogeneous 3 sites, even homogeneous sites always include some degree of uncertainty. Therefore, it is 4 necessary to take advantage of a proper method for interpolating the boreholes' data at the 5 construction location to achieve the soil spatial variability. In this study, to estimate the spatial 6 variability of the selected stochastic soil parameters from known data of the three boreholes at 7 the construction location (hypothetical borehole), the non-stationary random field model and 8 the geostatistical method was used. For this purpose, in the non-stationary random field model, 9 after averaging between the boreholes' data, the depth-dependent trends of the mean and 10 standard deviation of soil parameters are obtained through the nonlinear fitting. These results 11 are summarized in Table 2.

Table 2. Estimations of geotechnical parameters at construction location via non-stationary random field model

\begin{tabular}{|c|c|c|c|c|c|c|c|}
\hline $\begin{array}{c}\text { Layer } \\
\text { No. }\end{array}$ & $\begin{array}{c}\text { Depth } \\
(\mathrm{m})\end{array}$ & $\begin{array}{c}\text { PImean } \\
(\%) \\
\end{array}$ & $\begin{array}{c}\gamma_{\text {mean }} \\
\left(\mathrm{kN} / \mathrm{m}^{3}\right) \\
\end{array}$ & $\begin{array}{l}\left(V_{\mathrm{s}}\right)_{\text {mean }} \\
(\mathrm{m} / \mathrm{sec}) \\
\end{array}$ & $\sigma_{\mathrm{PI}}$ & $\sigma_{\gamma}$ & $\sigma_{\mathrm{vs}}$ \\
\hline $\begin{array}{l}1 \\
2\end{array}$ & $\begin{array}{l}0-2 \\
2-4\end{array}$ & $\begin{array}{l}6.44 \\
6.16\end{array}$ & $\begin{array}{l}16.94 \\
17.37\end{array}$ & $\begin{array}{l}167.2 \\
227.1\end{array}$ & $\begin{array}{l}0.72 \\
0.73\end{array}$ & $\begin{array}{l}0.16 \\
0.16\end{array}$ & $\begin{array}{l}22.53 \\
20.64\end{array}$ \\
\hline 3 & $4-6$ & 5.91 & 17.71 & 252.8 & 0.74 & 0.17 & 21.16 \\
\hline 4 & $6-8$ & 5.85 & 17.96 & 286.8 & 0.75 & 0.19 & 23.68 \\
\hline 5 & $8-10$ & 6.03 & 18.16 & 313.7 & 0.75 & 0.19 & 27.81 \\
\hline 6 & $10-12$ & 6.31 & 18.32 & 320.2 & 0.76 & 0.19 & 33.13 \\
\hline 7 & $12-14$ & 6.49 & 18.46 & 336.4 & 0.75 & 0.17 & 39.24 \\
\hline 8 & $14-16$ & 6.42 & 18.59 & 375.1 & 0.75 & 0.16 & 45.75 \\
\hline 9 & $16-18$ & 6.05 & 18.72 & 398.3 & 0.74 & 0.14 & 52.23 \\
\hline 10 & $18-20$ & 5.55 & 18.86 & 388.9 & 0.72 & 0.14 & 58.29 \\
\hline 11 & $20-22$ & 5.10 & 19.01 & 392.6 & 0.69 & 0.14 & 63.53 \\
\hline 12 & $22-24$ & 4.87 & 19.16 & 440.4 & 0.66 & 0.14 & 67.54 \\
\hline 13 & $24-26$ & 4.87 & 19.32 & 494.0 & 0.62 & 0.15 & 69.91 \\
\hline 14 & $26-28$ & 4.95 & 19.48 & 515.7 & 0.57 & 0.16 & 70.24 \\
\hline 15 & $28-30$ & 4.90 & 19.62 & 530.8 & 0.51 & 0.16 & 68.13 \\
\hline 16 & $30-32$ & 4.58 & 19.75 & 574.1 & 0.44 & 0.16 & 63.17 \\
\hline 17 & $32-34$ & 3.99 & 19.83 & 633.9 & 0.37 & 0.14 & 54.96 \\
\hline
\end{tabular}




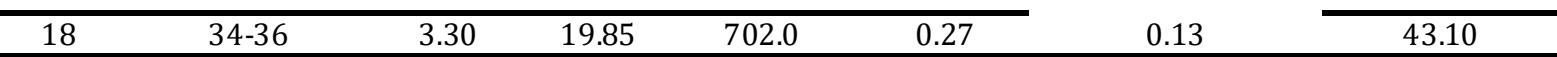

On the other hand, in the geostatistical method, the mean and standard deviation of soil parameters are determined using Kriging estimation. In this way, an exponentially decaying correlation function was utilized. Table 3 represents the results of the Kriging interpolation at the construction location. A sample calculation process for the first layer is presented in the Appendix.

Table 3. Estimations of geotechnical parameters at the construction location via the geostatistical method

\begin{tabular}{cccccccc}
\hline $\begin{array}{c}\text { Layer } \\
\text { No. }\end{array}$ & $\begin{array}{c}\text { Depth } \\
(\mathrm{m})\end{array}$ & $\begin{array}{c}\mathrm{PI}_{\text {mean }} \\
(\%)\end{array}$ & $\begin{array}{c}\gamma_{\text {mean }} \\
\left(\mathrm{kN} / \mathrm{m}^{3}\right)\end{array}$ & $\begin{array}{c}\left(\mathrm{V}_{\mathrm{s}}\right)_{\text {mean }} \\
(\mathrm{m} / \mathrm{sec})\end{array}$ & $\sigma_{\mathrm{PI}}$ & $\sigma_{\gamma}$ & $\sigma_{\mathrm{vs}}$ \\
\hline 1 & $0-2$ & 7.12 & 17.20 & 172.6 & 0.69 & 0.11 & 11.61 \\
2 & $2-4$ & 7.07 & 17.92 & 248.7 & 0.52 & 0.16 & 14.02 \\
3 & $4-6$ & 5.83 & 18.14 & 265.0 & 0.51 & 0.11 & 14.65 \\
4 & $6-8$ & 5.31 & 18.39 & 311.1 & 0.58 & 0.14 & 32.08 \\
5 & $8-10$ & 5.77 & 18.55 & 325.0 & 0.48 & 0.14 & 25.47 \\
6 & $10-12$ & 7.09 & 18.73 & 354.2 & 0.50 & 0.13 & 34.26 \\
7 & $12-14$ & 8.06 & 18.66 & 339.8 & 0.53 & 0.20 & 26.77 \\
8 & $14-16$ & 7.57 & 19.15 & 421.2 & 0.69 & 0.09 & 36.87 \\
9 & $16-18$ & 6.75 & 19.21 & 450.2 & 0.63 & 0.13 & 38.80 \\
10 & $18-20$ & 5.23 & 19.29 & 421.0 & 0.97 & 0.08 & 44.39 \\
11 & $20-22$ & 5.08 & 19.45 & 420.8 & 0.51 & 0.12 & 27.52 \\
12 & $22-24$ & 5.43 & 19.47 & 477.0 & 0.44 & 0.10 & 40.15 \\
13 & $24-26$ & 5.18 & 19.87 & 523.8 & 0.29 & 0.11 & 45.88 \\
14 & $26-28$ & 5.18 & 20.04 & 580.4 & 0.32 & 0.16 & 76.31 \\
15 & $28-30$ & 4.84 & 20.00 & 576.1 & 0.47 & 0.12 & 69.68 \\
16 & $30-32$ & 4.96 & 20.12 & 602.1 & 0.32 & 0.11 & 64.25 \\
17 & $32-34$ & 4.37 & 20.23 & 655.8 & 0.30 & 0.12 & 35.83 \\
18 & $34-36$ & 3.60 & 20.37 & 744.9 & 0.27 & 0.10 & 21.87 \\
\hline
\end{tabular}

Comparing the estimated soil parameters in Table 2 and 3 reveal that the estimated shear wave velocities and unit weights by the non-stationary random field are lower than those by the geostatistical method. As a result, it can be stated that the soil parameters predicted by the random field method lead to softer behavior of soil compared to the geostatistical method.

Among the statistical distributions, researchers widely use log-normal distribution to model the uncertainty of soil parameters because it has a zero probability of producing negative numbers. In this study, in order to track the effect of soil properties variation on the ground responses, the log-normal non-stationary random field has been employed to generate profiles of the selected stochastic parameters $\left(\mathrm{V}_{s}, \gamma\right.$, and PI). As well as in the geostatistical method, the selected stochastic parameters were modeled by the log-normal distribution.

Figs. 6 to 11 represent the variability of $V_{s}, \gamma$, and PI at the construction location by the two methods. In each figure, the Probability Density Function (PDF) of the fourth layer's corresponding parameters is plotted. Furthermore, in these figures, the red line corresponds to the mean value of soil parameters, and the gray lines are related to 2,000 realizations of the random profile. Since the boreholes' data (BH.1-3) indicates a low level of inhomogeneity, in both non-stationary random field and geostatistical methods, the scale of fluctuation is considered $45 \mathrm{~m}$ and $5 \mathrm{~m}$ in the horizontal and vertical directions, respectively [54]. It is worth mentioning that among these two implemented models, only the geostatistical method is capable of considering existing boreholes' locations in the estimations of soil parameters at the construction location. 


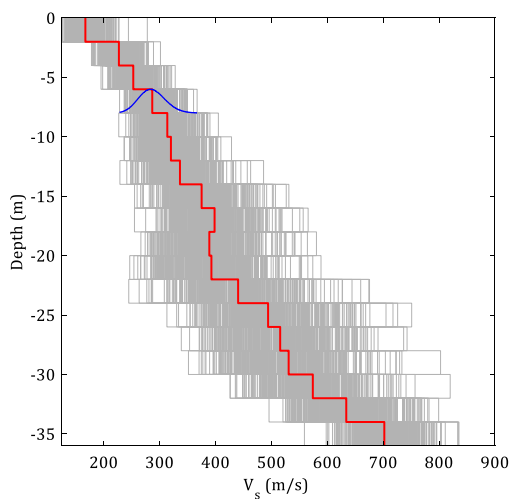

Fig. 6. Graphical variability of $\mathrm{V}_{\mathrm{s}}$ at the construction location by non-stationary random field

2

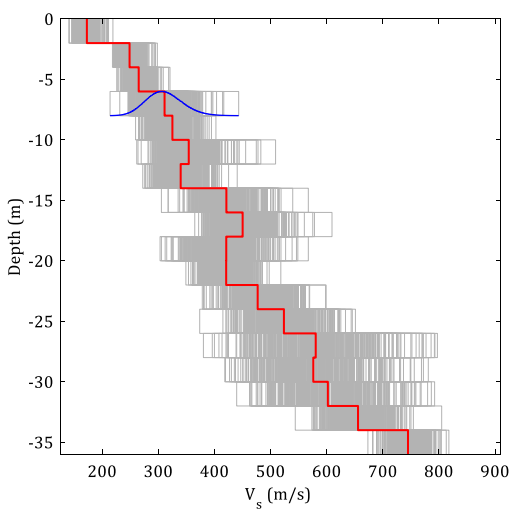

Fig. 9. Graphical variability of $V_{s}$ a the construction location by geostatistics

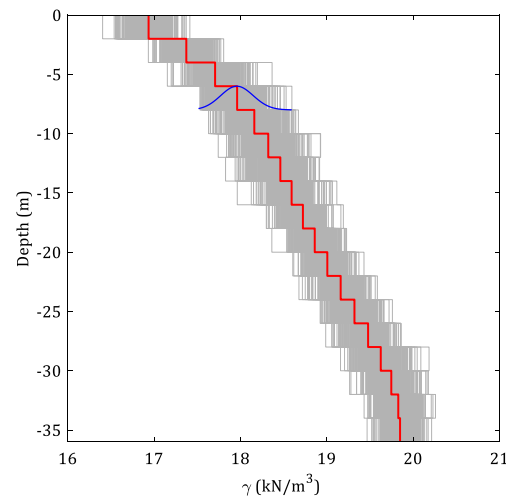

Fig. 7. Graphical variability of $\gamma$ in at the construction location by non-stationary random field

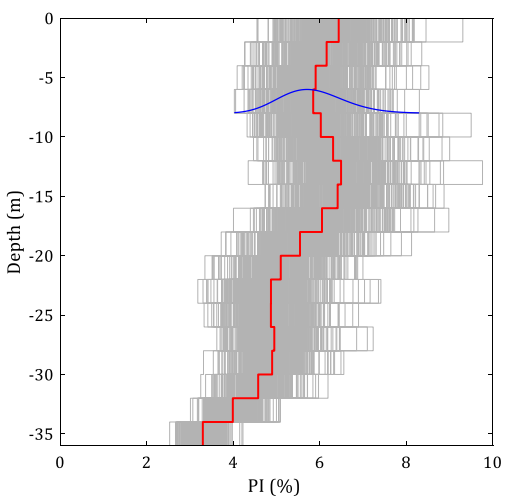

Fig. 8. Graphical variability of PI at the construction location by non-stationary random field

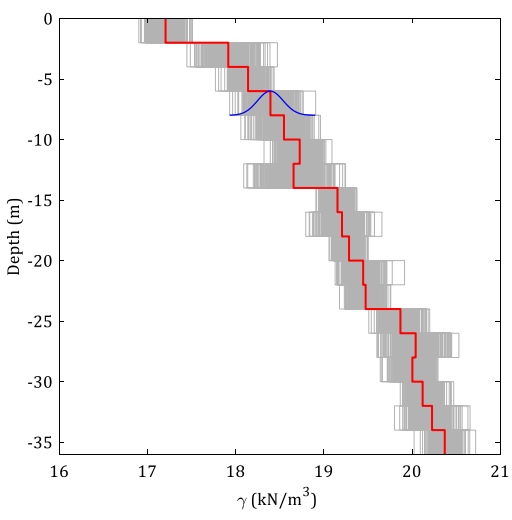

10. Graphical variability of
the construction location by geostatistics

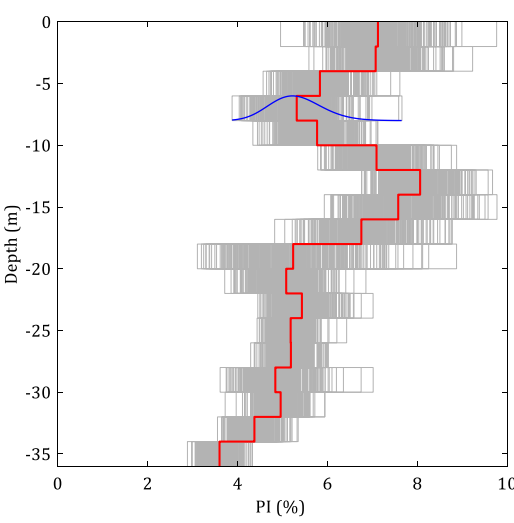

Fig. 11. Graphical variability of PI at the construction location by geostatistics

\section{Verification of the nonlinear developed code}

For verifying the accuracy of the developed MATLAB code in obtaining soil layers' response, an example problem was simulated by the nonlinear analysis method of the DEEPSOIL software [5] and the code. The mean values of soil parameters, which are provided in Table 3 utilized in this analysis as soil properties of the layers.

In order to ensure the mobilization of nonlinear soil behavior, it was necessary to apply a relatively strong earthquake to the soil profiles. Therefore, in the following analyses, the 1994 Meymand earthquake $\left(\mathrm{M}_{\mathrm{w}}=6.1\right)$ with the peak acceleration of $0.51 \mathrm{~g}$, which occurred on June 20, at about $84 \mathrm{~km}$ from Shiraz city, was considered as input motion at the bottom of the soil profile. Fig. 12 shows the 1994 Meymand earthquake acceleration time history.

The records of strong-motion acceleration instruments contain baseline offsets. Although this offset is small in the recorded acceleration, it can produce exaggerated displacements by double integration of the recorded acceleration. Thus, baseline corrections are necessary. Fig. 13 shows the baseline corrected and uncorrected time history of displacement input motion. In this way, the proposed procedure by Boore [56] is utilized to conduct baseline correction. The normalized modulus reduction and damping ratio curves corresponding to mean values of 
1 layers soil properties were estimated through the Darendeli [44] model are shown in Figs. 14 2 and 15.

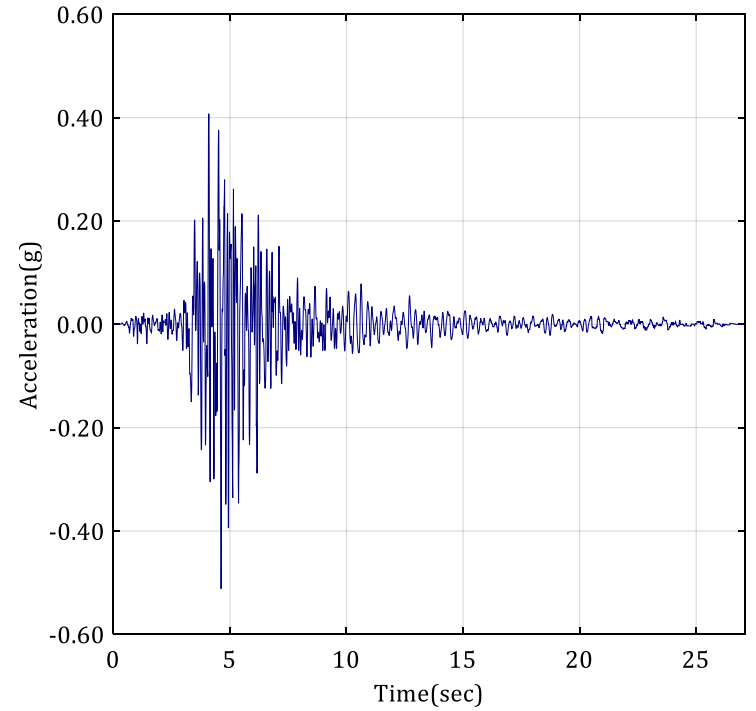

Fig. 12. Input acceleration the 1994 Meymand earthquake earthquake

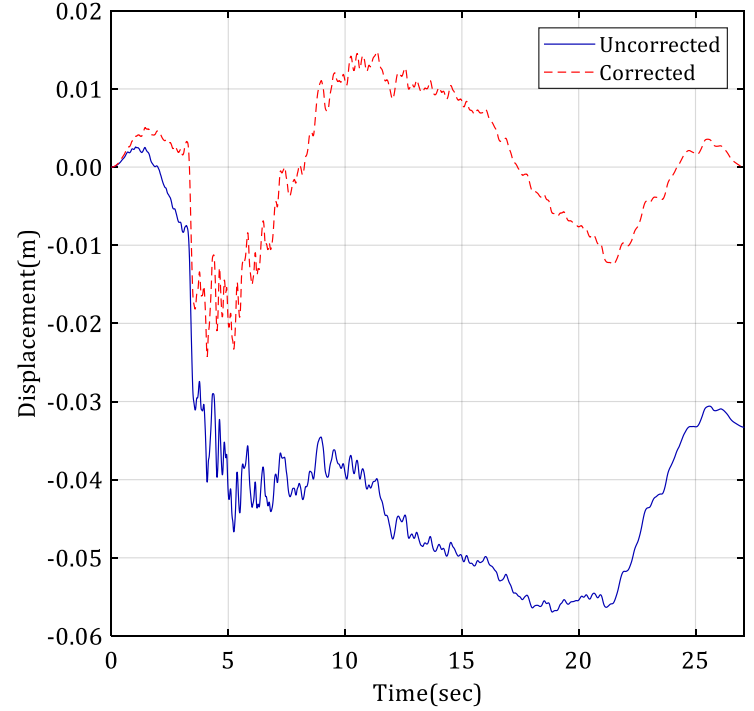

Fig. 13. Corrected and uncorrected time history of displacement input motion

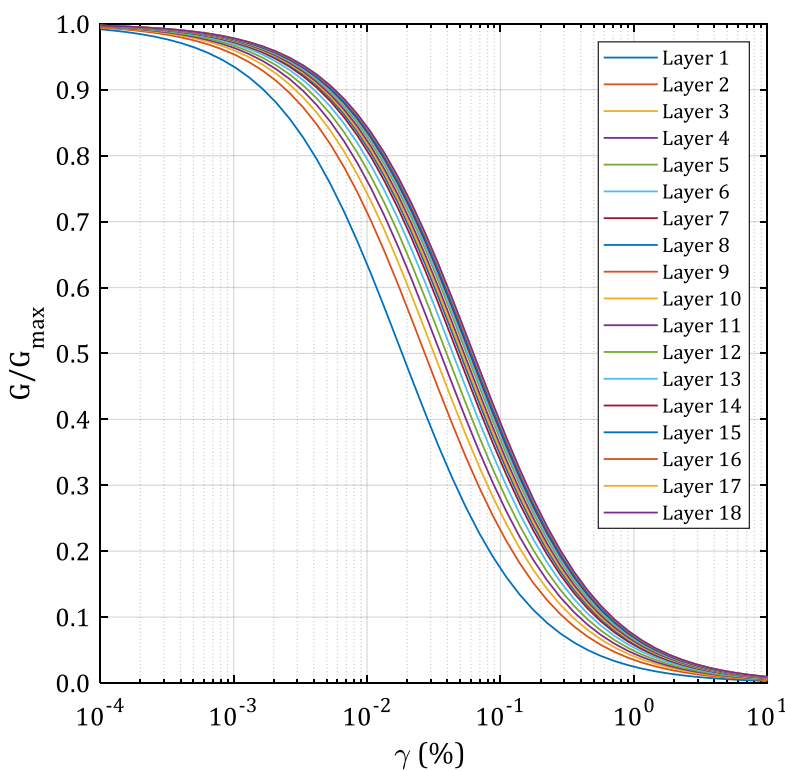

Fig. 14. Predicted normalized modulus reduction curves for the soil layers

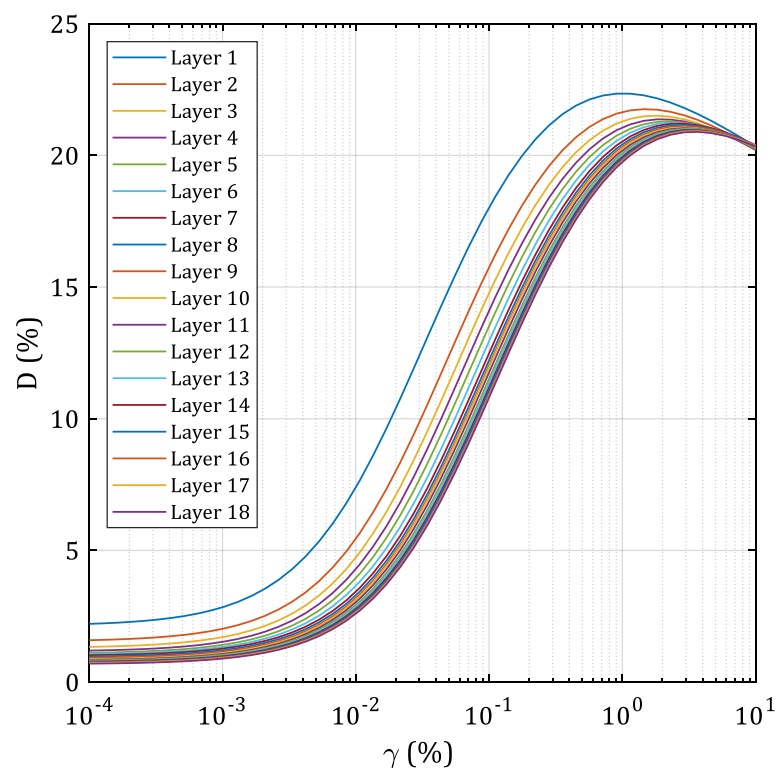

Fig. 15. Predicted damping ratio curves for the soil layers

The predicted absolute acceleration time histories, a close-up view from 3 sec to 7 sec time window, and $S_{a}$ of the surface layer for the proposed method and the DEEPSOIL are compared in Figs. 16 to 18, respectively. These graphs represent a good agreement between the predicted responses by the developed code and the DEEPSOIL. Fig. 19 demonstrates the predicted stress-strain loops through the proposed method and DEEPSOIL. This figure indicates that the output of the code provides a good match with DEEPSOIL. The slight mismatch in the results is due to differences in the employed soil models in the two programs (i.e., the modified 
1 Darendeli [44] model in developed code and the modified Kondner and Zelasko [48] in the 2 DEEPSOIL [5]). As expected, it shows that the Darendeli [44] model predicts a bit higher 3 damping through cycles.

Table 4 compares the developed code and DEEPSIOL program results, including the peak 5 of $S_{a}$, maximum and minimum values of acceleration, shear strain, and normalized shear stress $\left(\tau / \sigma^{\prime}\right)$. This table also emphasizes the acceptable agreement between the results of the two methods.

8

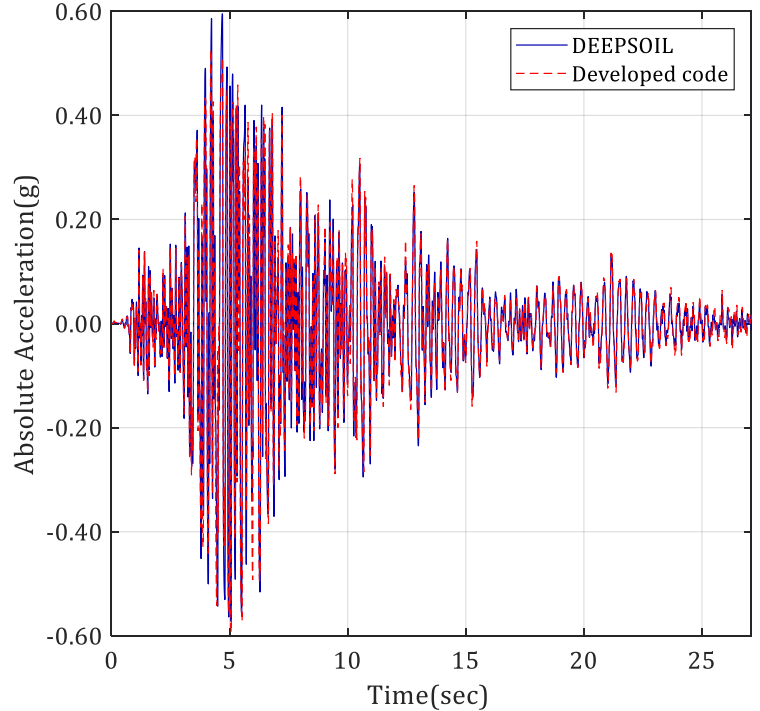

Fig. 16. Absolute acceleration time histories at the ground surface by the developed code and DEEPSOIL

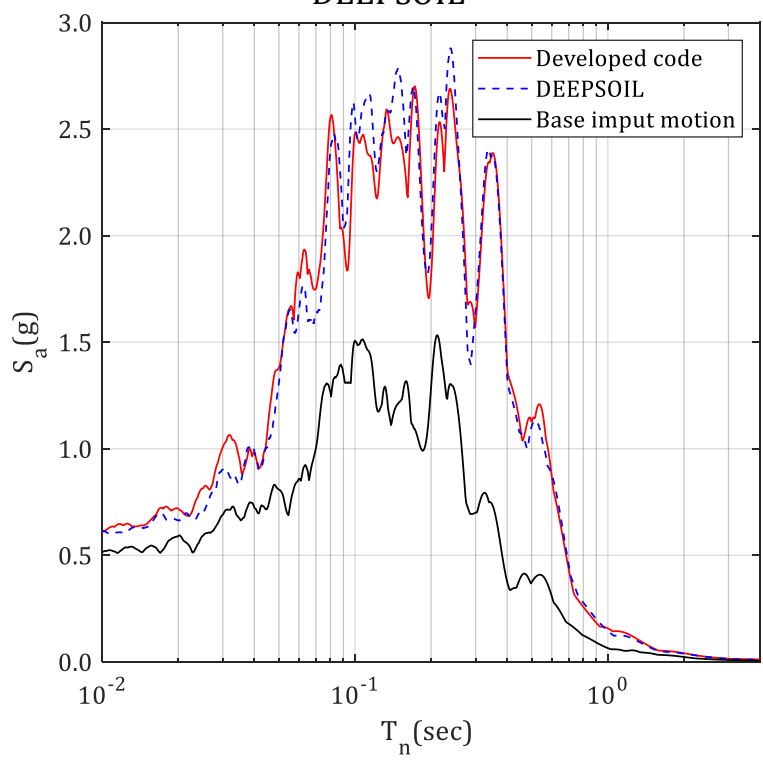

Fig. 18. Ground surface $S_{a}$ by the developed code and DEEPSOIL

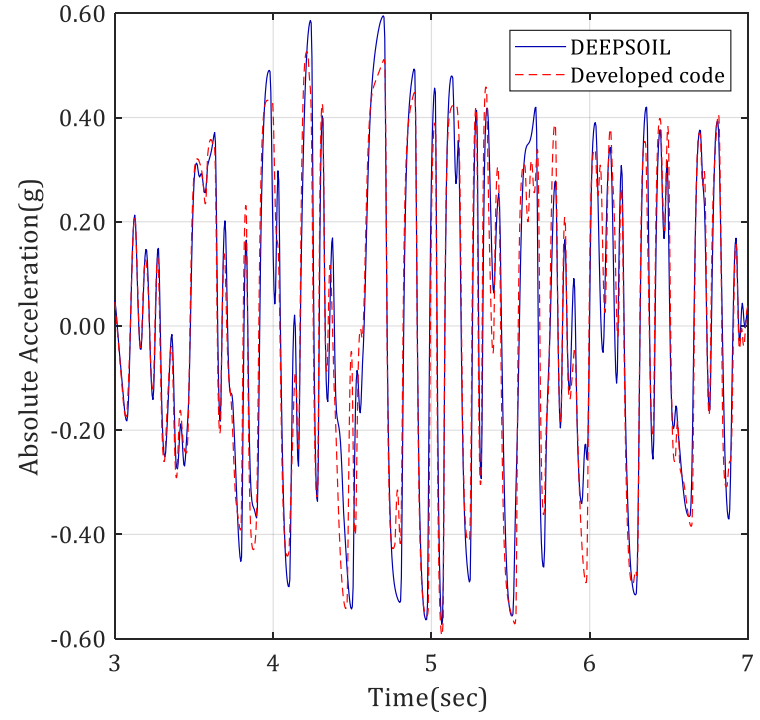

Fig. 17. A close-up view of absolute acceleration time histories for a time window from $3 \mathrm{~s}$ to $7 \mathrm{~s}$

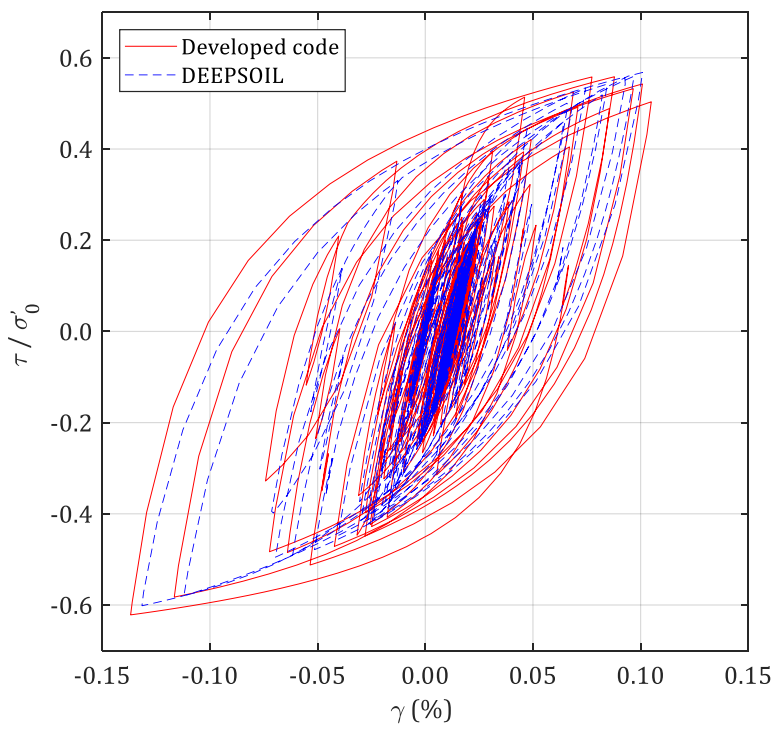

Fig. 19. Stress-strain loops predicted by the developed code and DEEPSOIL

Table 4. Comparison of the developed code and DEEPSOIL results
Method
Acceleration (g)
$\tau / \sigma_{0}^{\prime}$
$\gamma(\%)$
Peak of $S_{a}$ 


\begin{tabular}{|c|c|c|c|c|c|c|c|}
\hline & & & & \\
\hline & Min. & Max. & Min. & Max. & Min. & Max. & \\
\hline Developed code & -0.59 & 0.53 & -0.62 & 0.56 & -0.137 & 0.105 & 2.70 \\
\hline DEEPSOIL & -0.57 & 0.59 & -0.60 & 0.57 & -0.132 & 0.101 & 2.87 \\
\hline
\end{tabular}

\section{Stochastic analysis of the site}

As mentioned before, the main goal of this study is to consider the existing boreholes' location effects in stochastic nonlinear site response analysis through geostatistical methods. Therefore, to avoid further complexity in interpreting the results, loading and geometric parameters such as input motion and thickness layers were regarded as deterministic parameters. The main factors that could affect the nonlinear amplification and attenuation of soil profiles during earthquake excitations are the shear modulus and damping variation with strain.

Sensitivity analysis performed in previous studies on laboratory data of different soils illustrates that variation of soil shear modulus is more influenced by shear wave velocity, unit weight, and soil plasticity. Furthermore, the most effective parameters on soil damping are plasticity index and confining pressure $[43,44,57]$. Therefore, in the present study, the plastic index, shear wave velocity, and unit weight which significantly affect the nonlinear behavior of soil were selected as stochastic soil parameters. To this end, the proposed deterministic computer program was extended to perform stochastic input parameters generation and iterative calculation via MCS. In the next step of this study, the stochastic nonlinear ground response analysis was conducted using the generated random profiles (see section 7) to investigate the geostatistical method's applicability compared to the non-stationary random field.

The number of required Monte Carlo simulation depends on the desired level of confidence in the solution and the number of variables [58]. Since the required number of trials based on proposed statistical equations in literature has a high computational cost, fewer simulations are typically performed in the time-consuming dynamic simulations such as the nonlinear time-domain analyses [31]. Therefore, in this study, a statistical analysis was carried out to determine the required number of stochastic simulations for MCS. The mean of PGA is considered as the target parameter for checking the stability of stochastic analysis. The employed criterion for this stability analysis was based on a number of simulations where the average PGA variation for at least 30 consecutive numbers was less than $0.01 \mathrm{~g}$. As shown in Fig. 20 , when the number of simulations reaches 1,675 , the mean PGA of the surface layer becomes stable. Consequently, 1,800 simulations would be sufficient in stochastic analysis of the studied site. All the following stochastic results are obtained using 1,800 simulations. 


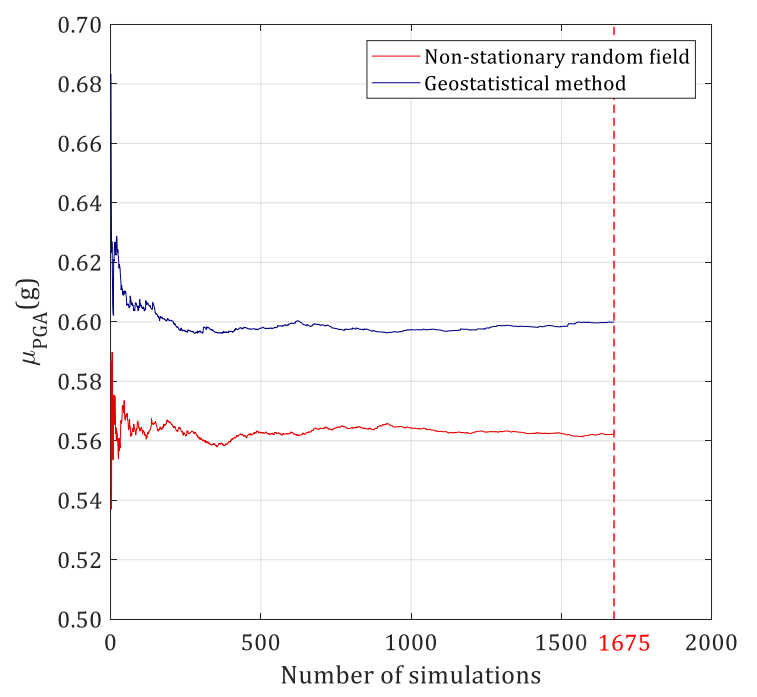

Fig. 20. Number of simulations versus mean PGA of the surface layer

\section{$1 \quad$ 10.Stochastic results of nonlinear ground response}

2

The stochastic results of seismic ground response can be described in PGD, PGA, maximum and minimum shear strain, surface acceleration response spectra, and amplification factor. These stochastic results will be described and compared for the non-stationary random field and geostatistical methods in the following subsections.

\subsection{Peak ground displacement}

Earthquakes can cause residual and permanent deformations, which generate excess pressure and stress concentration in subsurface structures. Peak ground displacements is an important parameter in earthquake-resistant design, especially for buried structures such as pipelines and deep foundations.

Figs. 21 and 22 illustrate the variation of nonlinear PGD through the soil profile due to selected stochastic soil parameters by the non-stationary random field and geostatistical methods, respectively. These graphs were plotted by obtaining the PGD of the ground surface with its time and capturing displacements of sub-layers at the corresponding time. Comparing the displacement on bedrock and the ground surface indicates the high potential of the site's profile in magnifying earthquake waves. Furthermore, these figures demonstrate that the uncertainties of input parameters, which are obtained using the non-stationary random field and geostatistical methods, caused the PGD of the ground surface to variate between $18.71 \mathrm{~mm}$ to $119.66 \mathrm{~mm}$ and $27.51 \mathrm{~mm}$ to $94.19 \mathrm{~mm}$, respectively. 


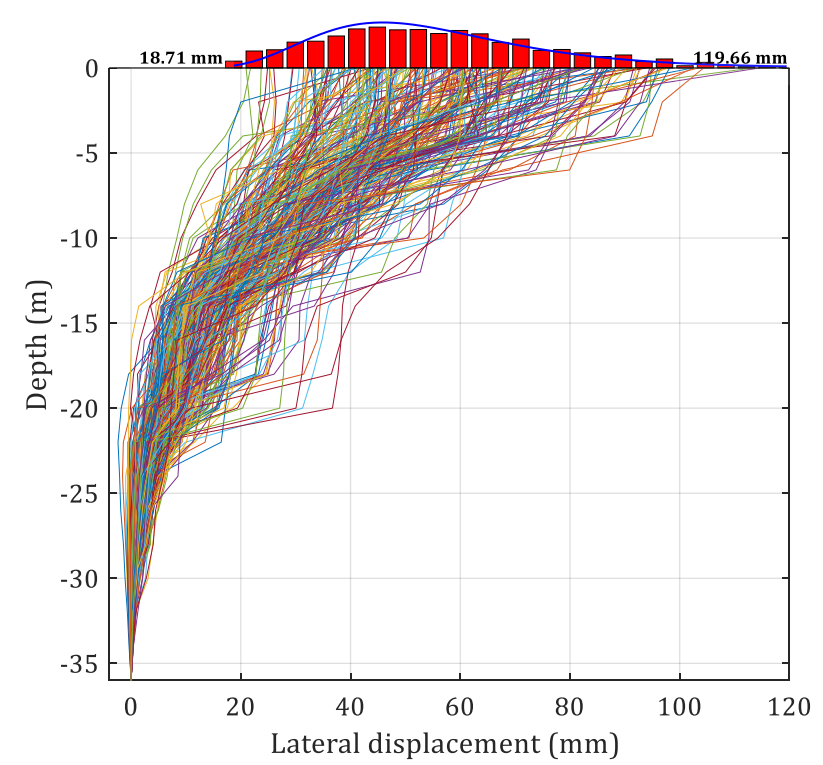

Fig. 21. Variation of ground surface PGD and corresponding lateral displacement of the soil sublayers by non-stationary random field

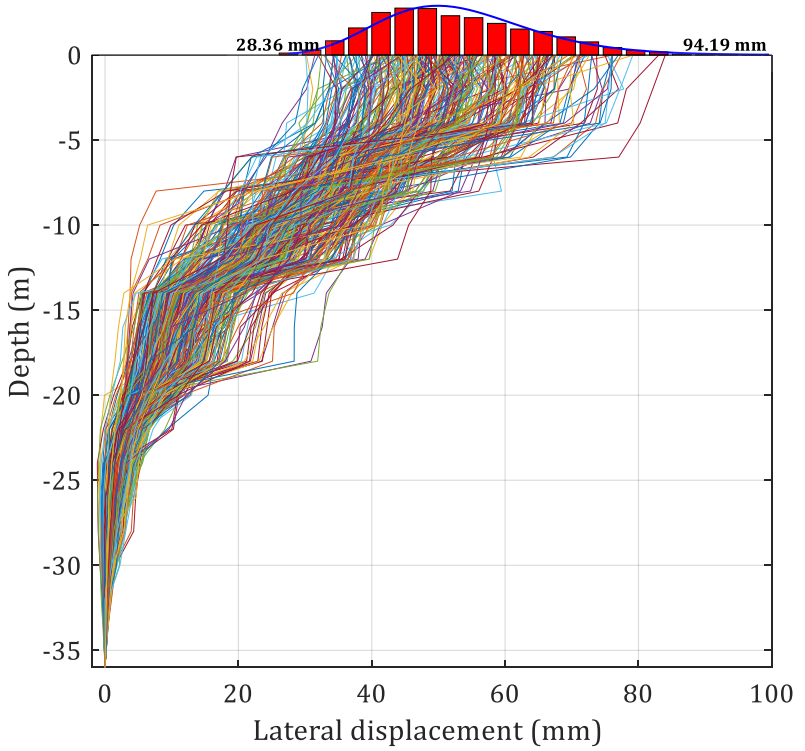

Fig. 22. Variation of ground surface PGD and corresponding lateral displacement of the soil sublayers by the geostatistical method

The variations of the ground surface PGD from both methods have a distribution near lognormal with the stochastic parameters summarized in Table 5. These stochastic parameters indicate that PGDs obtained using the geostatistical method have a slightly lower mean and less variation. It can be seen that the coefficient of variation for the PGD results of the geostatistical method is considerably lower than that of the non-stationary random field (i.e., about 13\%). These results are consistent with the concepts of the geostatistical method because by applying the spatial effect of the boreholes by this method, the final responses are closer to the borehole characteristics that are closer to the construction location. This matter would reduce the dispersion of the results.

Table 5. Stochastic parameters of the PGD

\begin{tabular}{cccccc}
\hline Method & Min. (mm) & Max. (mm) & Mean (mm) & Std. (mm) & COV (\%) \\
\hline Non-stationary random field & 18.71 & 119.66 & 55.88 & 19.57 & 35.02 \\
Geostatistical methods & 27.51 & 94.19 & 53.50 & 11.75 & 21.96 \\
\hline
\end{tabular}

\subsection{Variation of mobilized extremum shear strain of layers}

The extremum (maximum and minimum) shear strain profile determines what level of nonlinearity is mobilized at each soil layer. In this study, at each depth (the middle of each layer), the highest and lowest extremum of shear strains are extracted from the corresponding hysteresis stress-strain loops. Figs. 23 and 25 show the variation of extremum shear strain, respectively, obtained from the non-stationary random field and geostatistical methods. Figs. 24 and 26 depicted the calculated mean of extremum shear strain (red line) and mean plus or minus one (gray zone) and two (green zone) standard deviations for these two methods. It can be seen that the general trend of obtained shear strain is consistent with the results of previous researches [4,5]. So that after reaching a peak value, it approaches zero near the ground surface.

According to these figures, it can be inferred that in the studied site, through both nonstationary random field and geostatistical methods, the highest shear strain and, as a result, the 
most level of nonlinearity mobilized in the third layer ( $5 \mathrm{~m}$ depth). As well as it can be seen that the soil in the profiles which are generated by the non-stationary random field method experiences higher shear strain values, which is due to the fact that these profiles are softer compared to the generated profiles using the geostatistical method.

The obtained standard deviation of the extremum shear strain from the non-stationary random field method at all depths is greater than the corresponding value for the geostatistical method. The highest value of the extremum shear strain's standard deviation occurred at $5 \mathrm{~m}$ depth and equal to $0.11 \%$ and $0.08 \%$, respectively, for the non-stationary random field and 9 geostatistical methods.

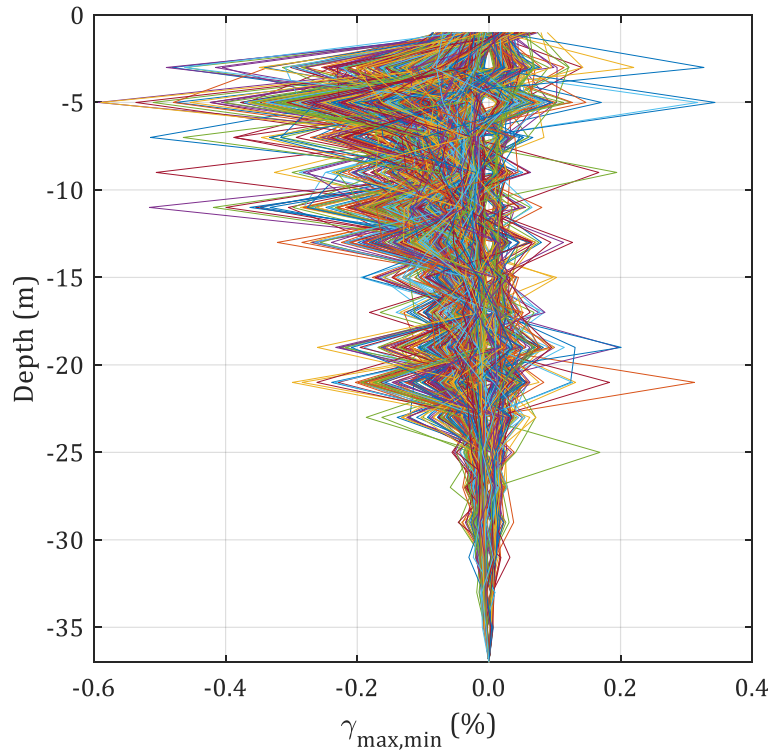

Fig. 23. Variation of extremum shear strain of layers by non-stationary random field

10

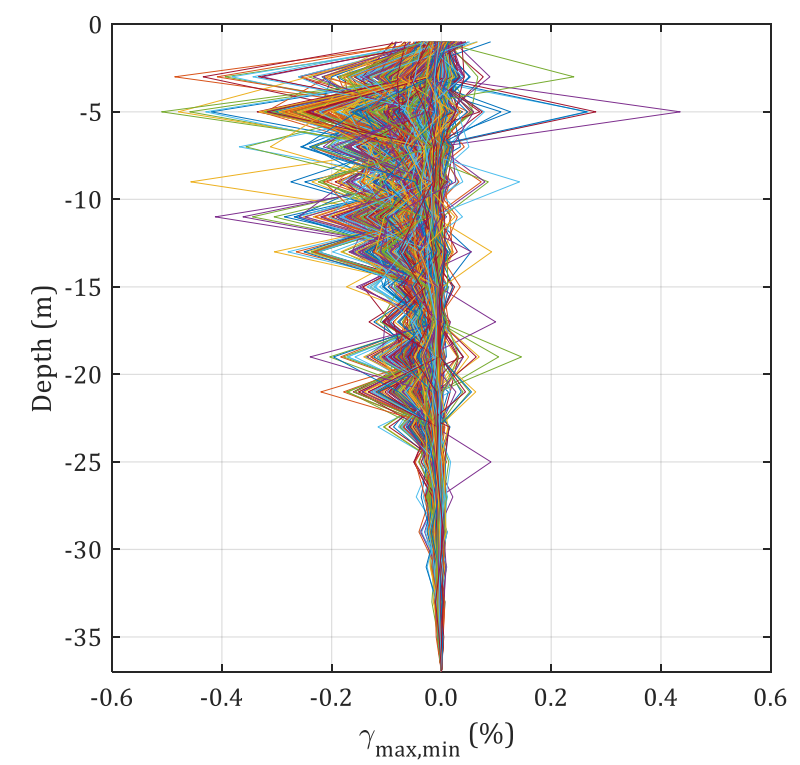

Fig. 25. Variation of extremum shear strain of layers by the geostatistical method

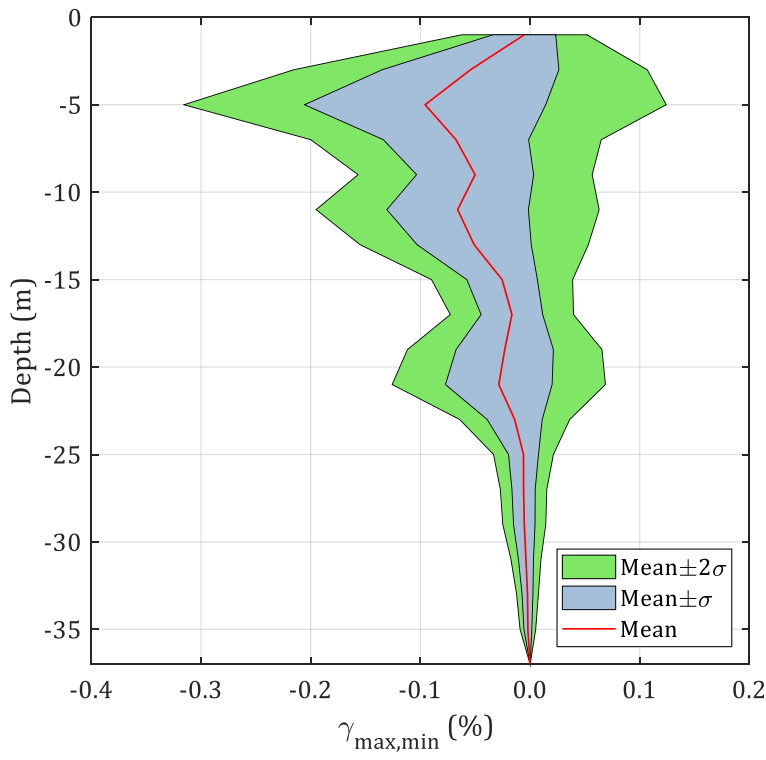

Fig. 24. The mean of extremum shear strain of layers plus or minus one and two standard deviations by non-stationary random field

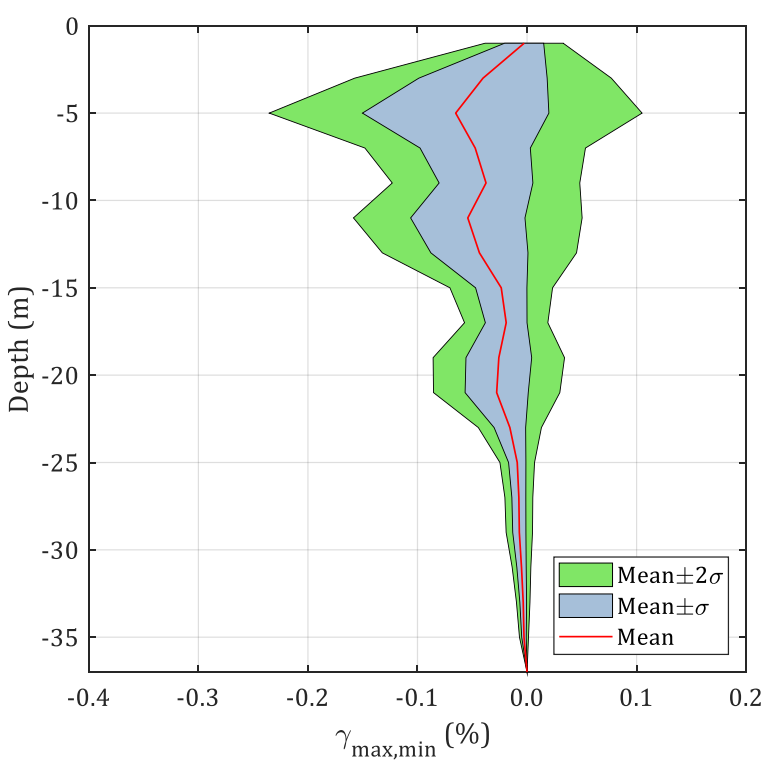

Fig. 26. The mean of extremum shear strain of layers plus or minus one and two standard deviations by the geostatistical method 
The acceleration response spectrum $\left(\mathrm{S}_{\mathrm{a}}\right)$ is a very useful tool in designing structures 3 under earthquake excitations. In this study, the stochastic nonlinear acceleration response spectrums have been estimated through the developed MATLAB code. Figs. 27 and 29 show the variation of nonlinear $S_{a}$, obtained from surface response acceleration for $5 \%$ structural damping for the non-stationary random field and geostatistical methods. Figs. 28 and 30 represent the calculated mean of $S_{a}$ at the ground surface (red line) and mean plus or minus one (gray zone) and two (green zone) standard deviations for these two methods. Additionally, the $9 \mathrm{~S}_{\mathrm{a}}$ of the input accelerograms at the bedrock is presented by the dashed line.

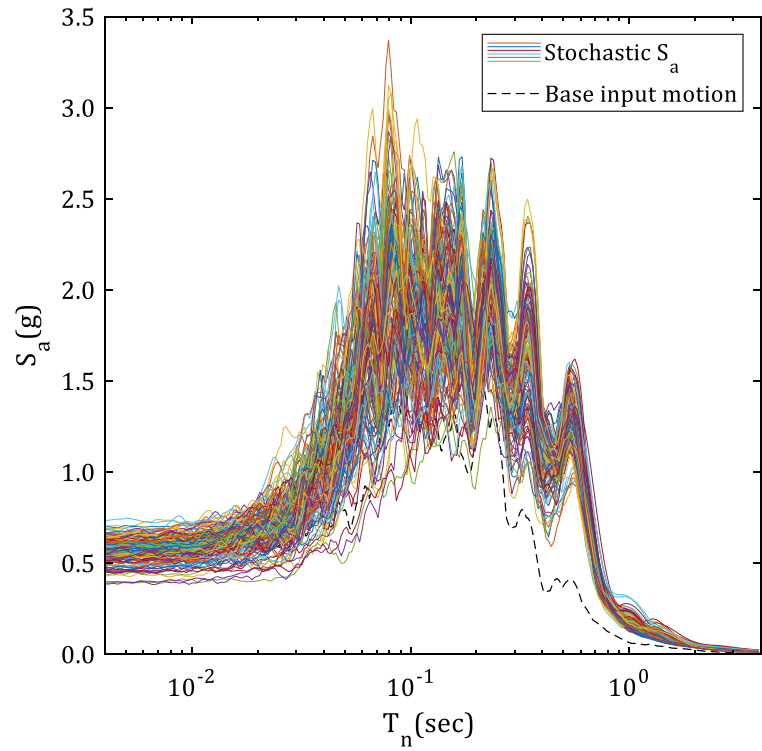

Fig. 27. The nonlinear stochastic $S_{a}$ at the ground surface by non-stationary random field

10

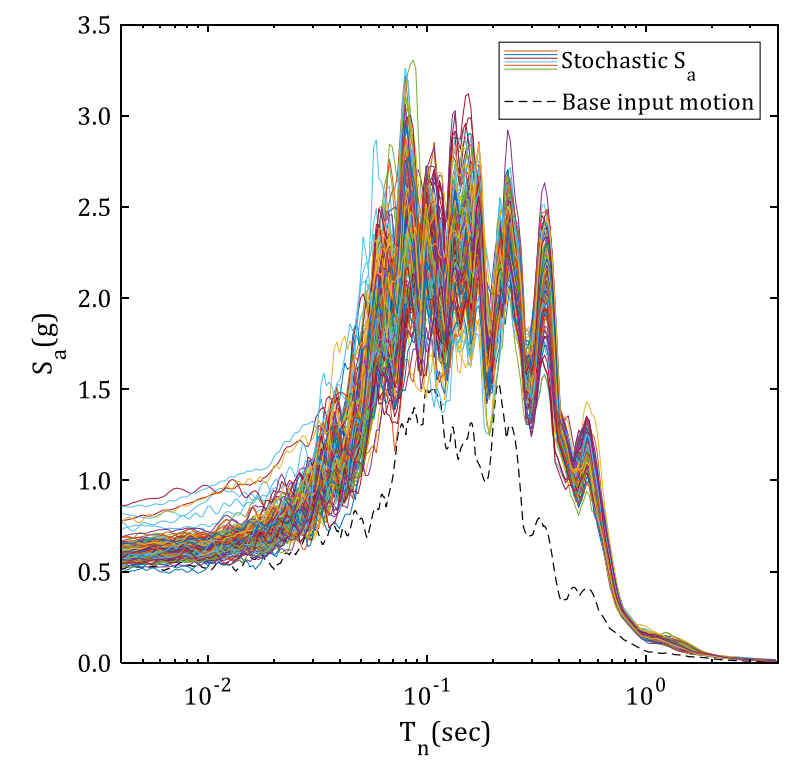

Fig. 29. The nonlinear stochastic $S_{a}$ at the ground surface by the geostatistical method

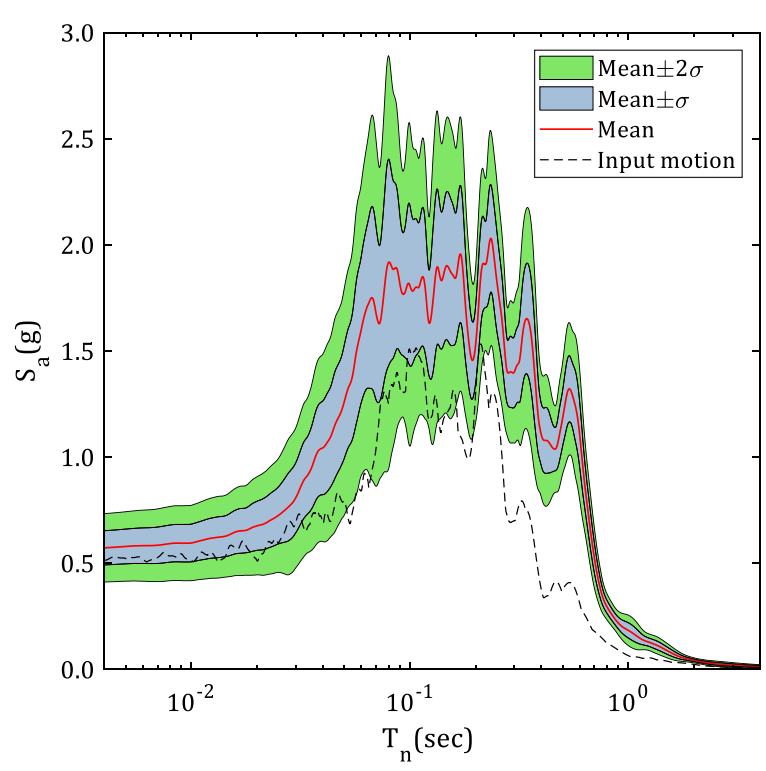

Fig. 28. The nonlinear mean $S_{a}$ plus or minus one and two standard deviations at the ground surface by non-stationary random field

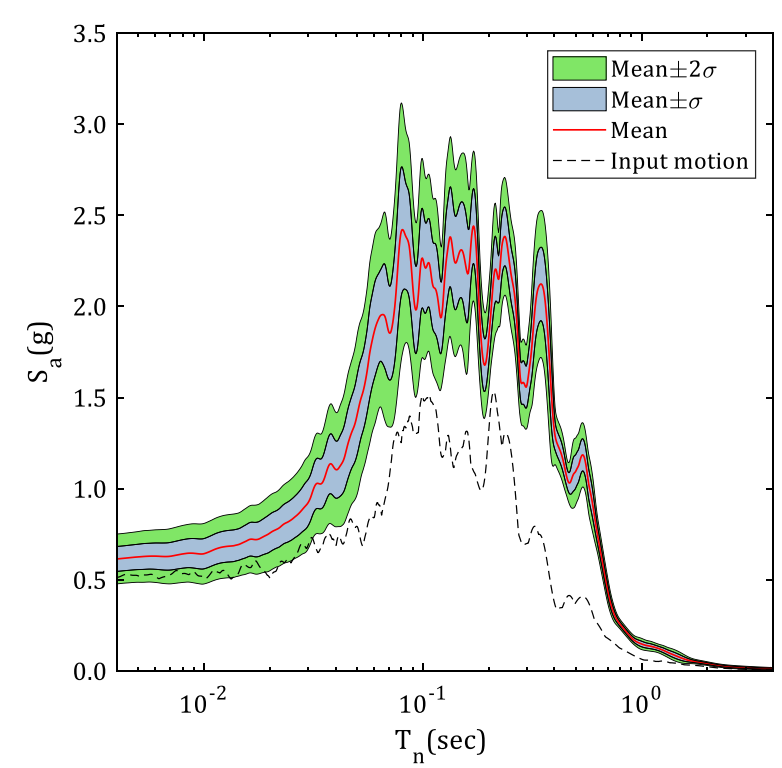

Fig. 30. The nonlinear mean $\mathrm{S}_{\mathrm{a}}$ plus or minus one and two standard deviations at the ground surface 
An approximation for determining the buildings' natural period is dividing the number of stories by 10. Natural periods vary from about $0.1 \mathrm{sec}$ to $0.5 \mathrm{sec}$ for one to a four-story building, respectively. Other factors, such as the building's structural system, construction materials, and geometric characteristics, also affect the period, but height is the most important factor [59]. Based on Figs. 27 to 30, it can be concluded that in the assessed site by the considered earthquake, buildings with short and medium height are more affected while the high-rise buildings are not influenced significantly.

Figs. 31 and 32 compare the variation of the mean and the COV of $S_{a}$ for the nonstationary random field and geostatistical methods. Fig. 31 illustrates that for the geostatistical method at periods less than $0.47 \mathrm{sec}$ (red dash line), the mean of $S_{a}$ is above that of the nonstationary random field. This matter is completely consistent with predicted the profiles by the two methods and the soils' nonlinear seismic behavior. So that, by comparing Figs. 6 and 9, it can be concluded that the profiles generated by the geostatistical method are stiffer than those of non-stationary random field, so it was expected that the $S_{a}$ obtained from these profiles have higher values in low periods and vice versa lower values in high periods. In contrast, the profiles predicted by the non-stationary random field resulted in higher $S_{a}$ values at high periods due to being softer.

Fig. 32 indicates that the COV of $\mathrm{S}_{\mathrm{a}}$ obtained from the non-stationary random field method is bigger than that of the geostatistical method. By comparing Figs. 31 and 32, it can be inferred that at the studied site, the most critical period is about $0.08 \mathrm{sec}$ (green dash line). Because at this point, both the mean of $S_{a}$ and its COV are high. Therefore, in this site with the considered earthquake, structures with natural periods close to $0.008 \mathrm{sec}$ are more critical than others.

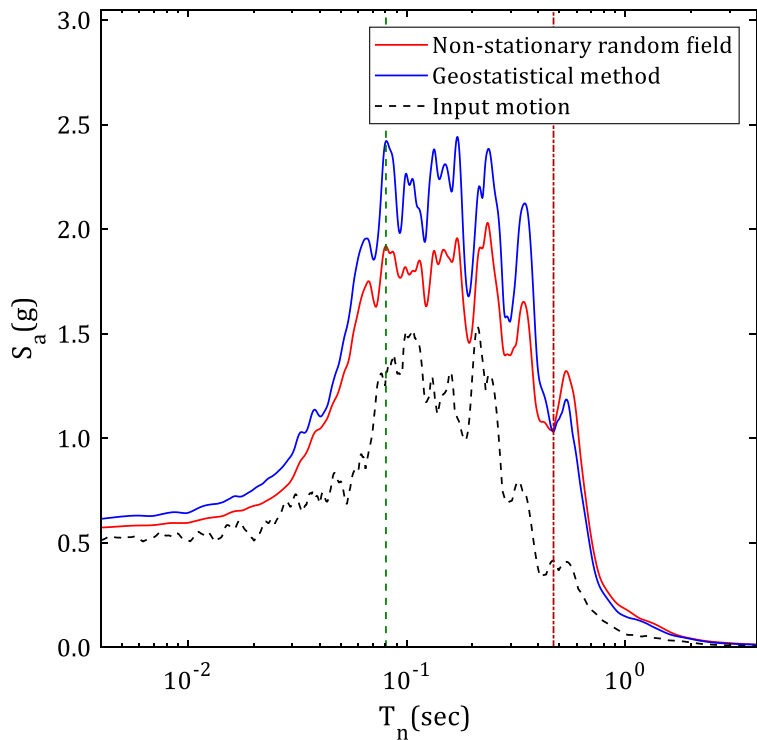

Fig. 31. The mean $S_{a}$ of the non-stationary random field and geostatistical methods

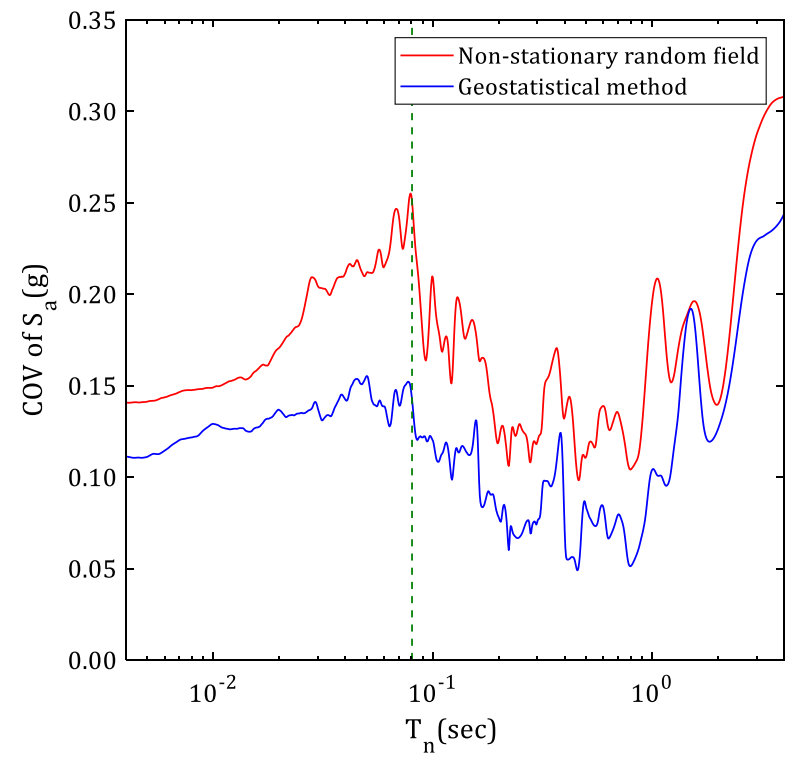

Fig. 32. The COV of $S_{a}$ for the non-stationary random field and geostatistical methods 
Peak ground acceleration is defined as the maximum amplitude of absolute acceleration time history. The PGA is the most commonly used ground motion parameter in engineering applications, especially in building codes and earthquake-resistant design. Fig. 33 shows the bar chart and fitted probability density function of the site PGA for the non-stationary random field and geostatistical methods with the stochastic parameters summarized in Table 5. It can be seen that the variations of the ground surface PGA from both two methods have a distribution close to normal. Fig. 33 also indicates that the PGA distribution from the geostatistical methods has a bigger mean value than that of the non-stationary random field. Furthermore, the dispersion of PGAs from the non-stationary random field is higher than the geostatistical method. These results are mostly due to the boreholes' location effects in the geostatistical method because in the studied site, the soil obtained from the borehole closer to the construction location was stiffer and its impact is considered in the generated stochastic profiles.

Fig. 34 shows the Complementary Cumulative Distribution Function (CCDF) of PGAs at the surface for the non-stationary random field and geostatistical methods. The CCDF determines how often the random variable is above a particular level. According to Table 5 and the obtained mean PGA for the non-stationary random field method $(0.56 \mathrm{~g})$, the probability of occurrence of PGAs can be determined using Fig. 34. This figure represents that the probability of occurring PGAs equal to or greater than $0.56 \mathrm{~g}$ for the non-stationary random field and geostatistical method is about $50 \%$ and $75 \%$, respectively. In other words, the occurrence of PGAs greater than 0.56 is much more likely in the geostatistical method.

The mean, standard deviation, and coefficient of variation for both methods are presented in Table 6. The results in this table indicate that COV for the non-stationary random field is higher than the geostatistical method; therefore, the geostatistical method's results include a lower level of uncertainties.

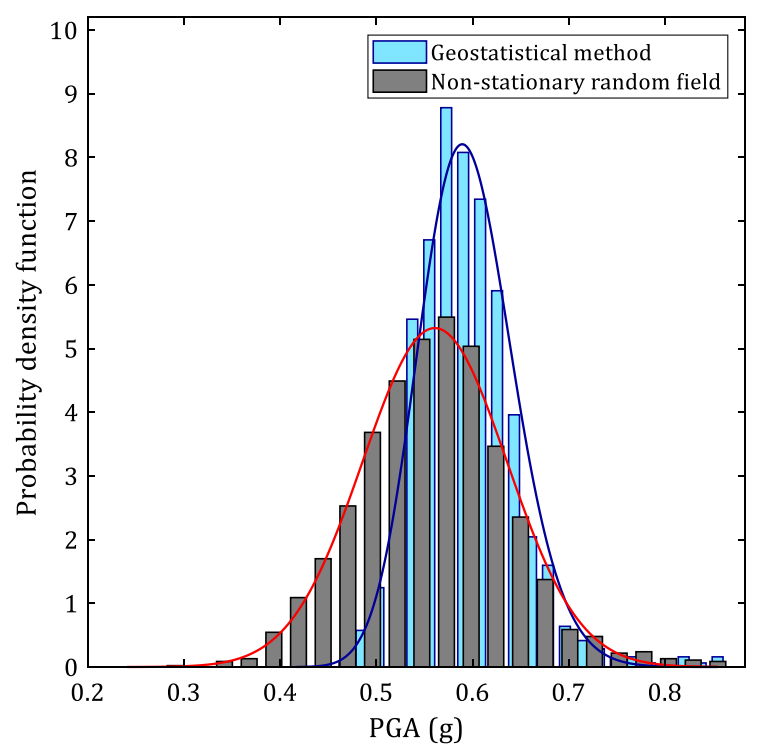

Fig. 33. The predicted PDF of PGA at the site surface for the non-stationary random field and geostatistical methods

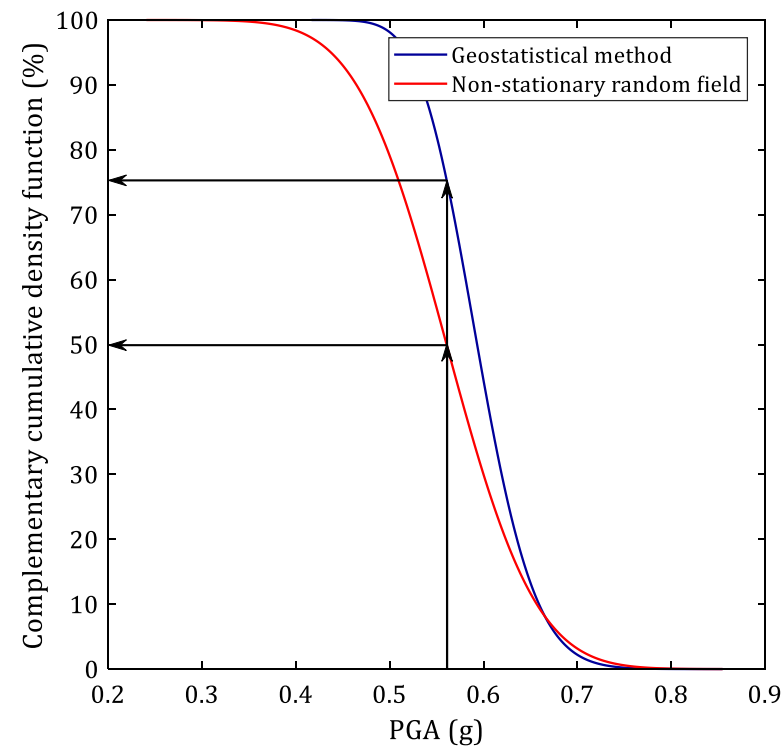

Fig. 34. The CCDF of PGA at the site surface for the non-stationary random field and geostatistical methods

Table 6. Stochastic parameters of the PGA

$\begin{array}{lll}\text { Analysis type } & \text { Mean }(\mathrm{g}) & \text { Std.(g) }\end{array}$
$\operatorname{COV}(\%)$ 


\begin{tabular}{cccc}
\hline Non-stationary random field & 0.56 & 0.08 & 14.29 \\
Geostatistical methods & 0.60 & 0.05 & 8.33 \\
\hline
\end{tabular}

1

2

3

4

5

6

7

8

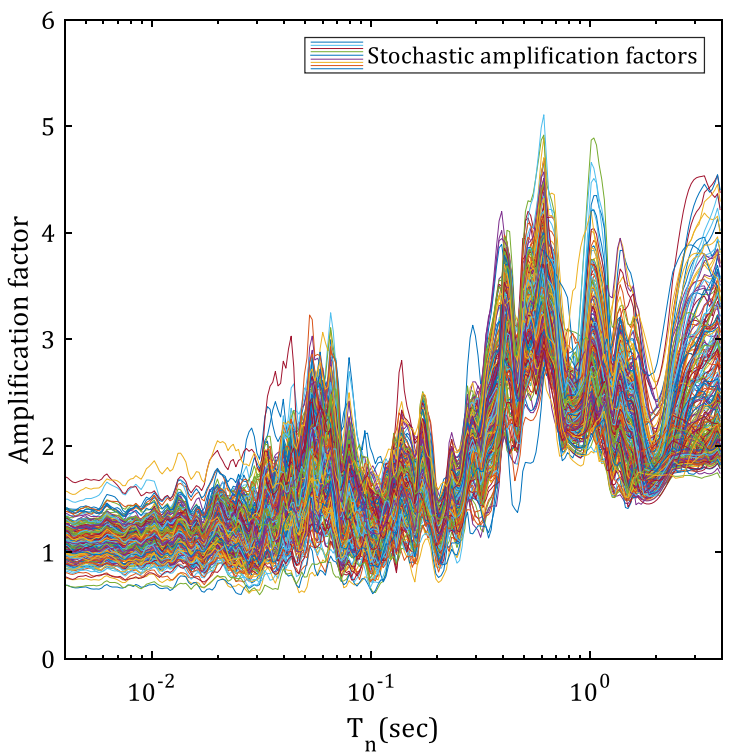

Fig. 35. Stochastic amplification factor at the ground surface by non-stationary random field

9

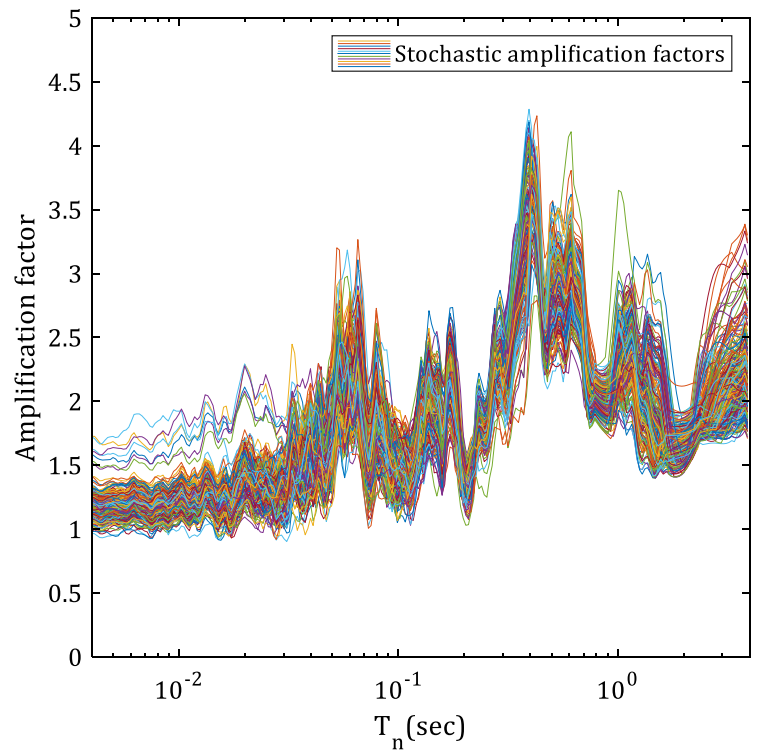

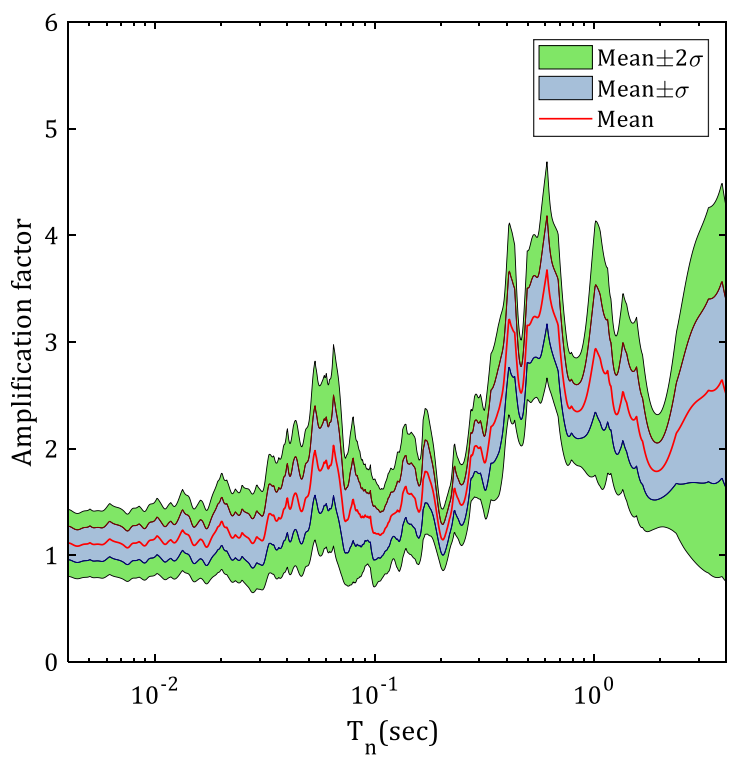

Fig. 36. The mean amplification factor plus or minus one and two standard deviations at the ground surface by non-stationary random field

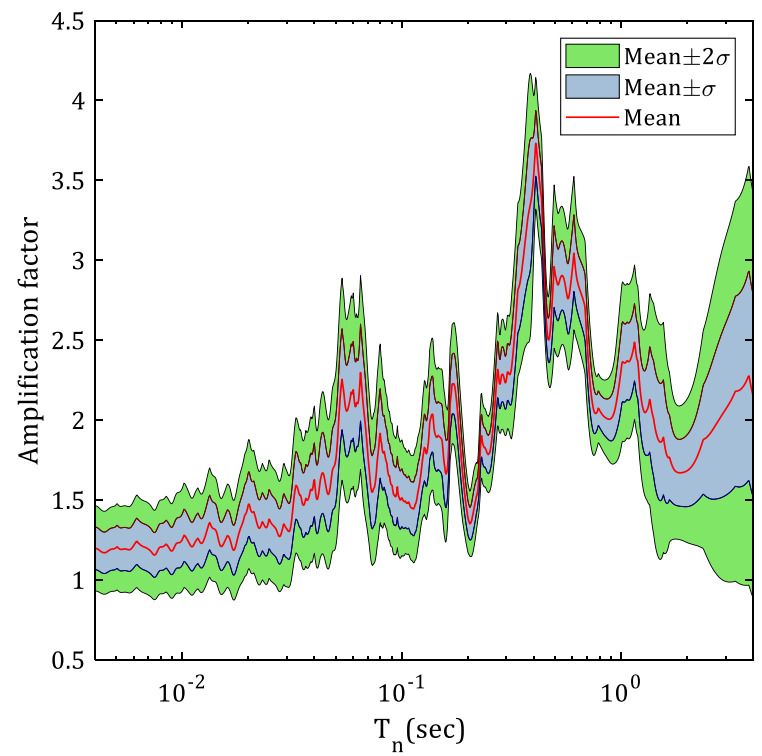


Fig. 37. Stochastic amplification factor at the ground surface by the geostatistical method
Fig. 38. The mean amplification factor plus or minus one and two standard deviations at the ground surface by the geostatistical method

Figs. 39 and 40 compare the mean and COV variation of the predicted site's amplification factor for the non-stationary random field and geostatistical methods. Fig. 39 represents that the peak of the amplification factor occurs at periods about $0.6 \mathrm{sec}$ and $0.4 \mathrm{sec}$ for the nonstationary random field and geostatistical method, respectively. It also demonstrates that the amplification factor of the geostatistical method at periods less than $0.47 \mathrm{sec}$ (green dash line) is above that of the non-stationary random field, and after this point, the amplification factor of the non-stationary random field is higher. This issue is resulting from the employing of boreholes' location effect (spatial effect of boreholes) in the geostatistical method. In other words, at the studied site, the BH.2 is closer to the construction location. Since BH.2 is relatively stiffer than the other two boreholes, the amplification factor of generated profiles by the geostatistical method is higher at lower periods. Furthermore, the amplification factor obtained by the non-stationary random field is higher at higher periods (Because it is composed of softer soils).

Fig. 40 shows that the COV of the amplification factors obtained from the non-stationary random field method is greater than that of the geostatistical method. This issue demonstrations the effect of the geostatistical method in reducing the dispersion of responses.

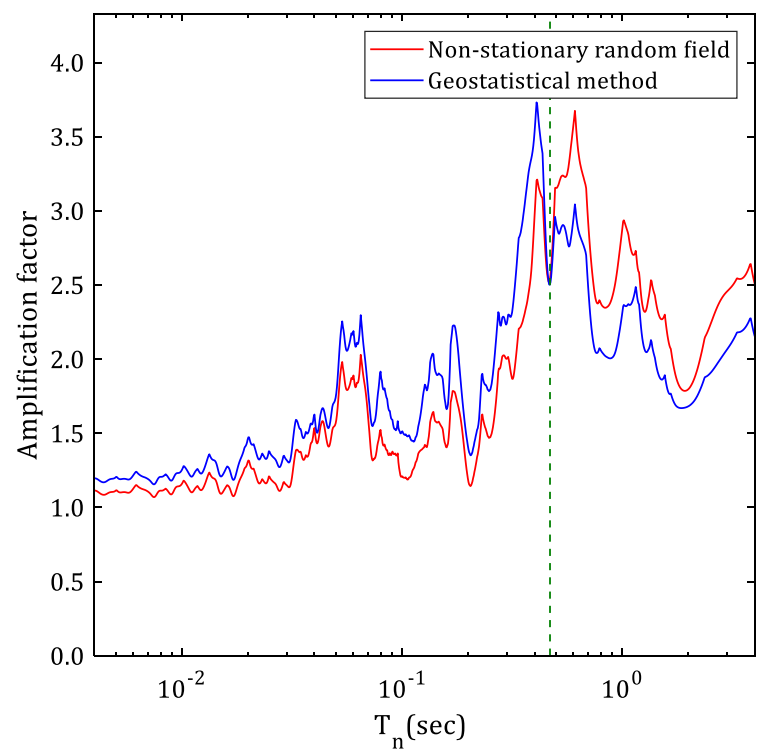

Fig. 39. The mean amplification factor of the nonstationary random field and geostatistical methods

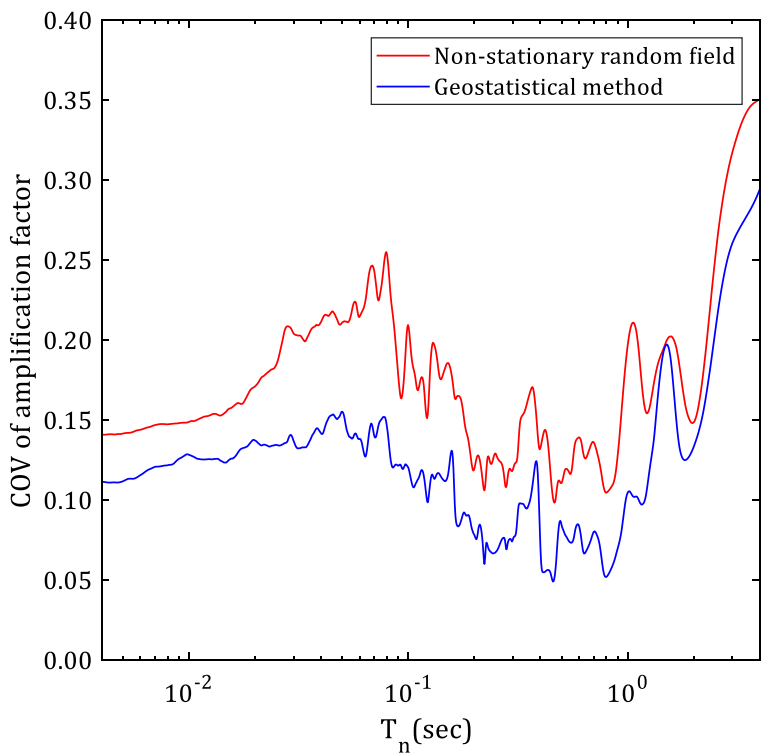

Fig. 40. The COV of the amplification factor for the non-stationary random field and geostatistical methods

\section{Discussion}

In this section, the obtained stochastic seismic responses from the studied site are discussed. The mean value of responses and their dispersions are examined through two 
1 different perspectives: nonlinear soil attenuation mechanism and uncertainties of the ground responses.

\subsection{Nonlinear soil attenuation mechanism}

To assess the nonlinear attenuation mechanism of soil behavior, the obtained mean values of stochastic ground responses are compared for the non-stationary random field and geostatistical methods.

Table 7 represents the mean of the stochastic responses from the non-stationary random field and geostatistical methods. It can be seen that the use of the non-stationary random field method leads to larger ground displacements, shear strain, velocity response spectrum $\left(S_{v}\right)$ and displacement response spectrum $\left(S_{d}\right)$. In contrast, the geostatistical method provides larger surface accelerations, $S_{a}$, and amplification factors, which is due to the fact that the profiles generated by the non-stationary random field are softer than those by the geostatistical method (i.e., they have less velocity and shear modulus). These results are in agreement with field observations and the findings reported by other researchers in the nonlinear attenuation behavior of soft soils under large earthquake excitations [60, 61]. Fig. 41 was originally drawn by Idriss [60] and later confirmed in subsequent researches [61]. This figure indicates that the occurrence of intense (i.e., PGA $>0.43 \mathrm{~g}$ ) earthquakes at sites with soft and medium soils can activate the nonlinear attenuation mechanism (called 'deamplification'), a mechanism which leads to lower PGA and higher shear strain and surface displacement, and instigates move of the predominant period toward the long-period range by increasing the input motion intensity in soft soil sites.

In order to provide a better evaluation of the present study results, the authors added the mean of PGA through the non-stationary random field and geostatistical methods in Fig. 41. Since the peak acceleration of the considered input motion is $0.51 \mathrm{~g}$, it is susceptible to be able to initiate the nonlinear attenuation mechanism. On the other hand, since the generated profiles using the non-stationary random field are softer than those of the geostatistical method, more nonlinear attenuation has occurred in the seismic responses attained from the non-stationary random field. Therefore, the mean stochastic PGA through the non-stationary random field is lower than those acquired from the geostatistical method.

Table 7. Mean of stochastic responses

\begin{tabular}{ccc}
\hline Parameter & Non-stationary random field & Geostatistical method \\
\hline Mean of PGD (mm) & 55.88 & 53.50 \\
Absolute peak of $\gamma_{\max , \min }(\%)$ & 0.59 & 0.50 \\
Peak of mean $\mathrm{S}_{\mathrm{a}}(\mathrm{g})$ & 2.03 & 2.44 \\
Peak of mean $\mathrm{S}_{\mathrm{v}}(\mathrm{m} / \mathrm{s})$ & 1.26 & 1.24 \\
Peak of mean $\mathrm{S}_{\mathrm{d}}(\mathrm{mm})$ & 100.8 & 87.0 \\
Mean of PGA (g) & 0.56 & 0.60 \\
Peak of the mean amplification factor & 3.60 & 3.70 \\
\hline
\end{tabular}




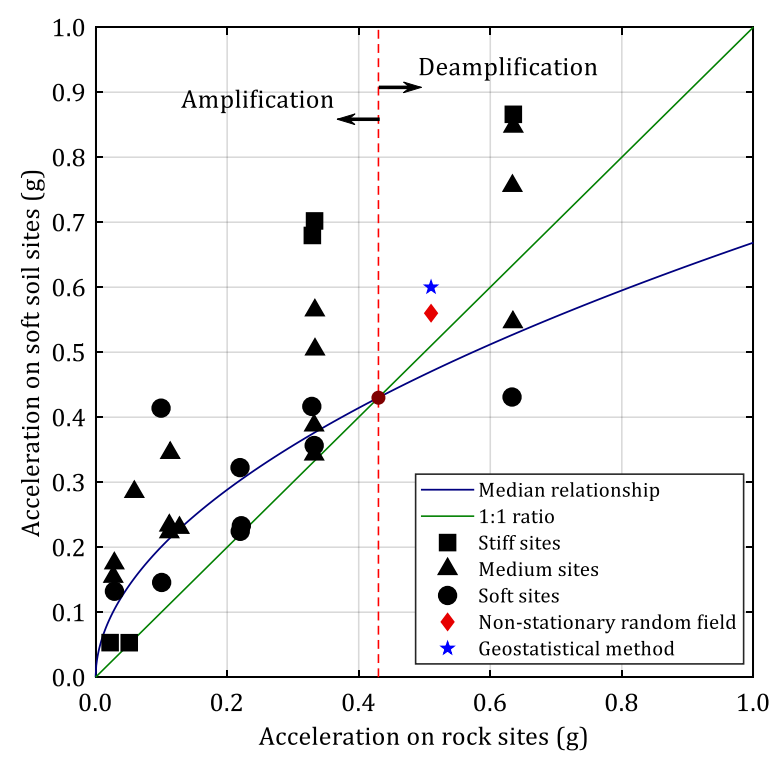

Fig. 41. Variations of amplification characteristics associated with nonlinear soil behavior

\section{11.2. Comparing the uncertainties of the ground responses}

2

In this section, uncertainties in ground responses with respect to the considered stochastic soil parameters are discussed. Table 8 compares the COVs of different seismic responses at the ground surface through the non-stationary random field and geostatistical methods. This table reveals that, among these surface responses, the PGD and PGA reflect the highest and lowest dispersions due to uncertainties of soil properties. It can also be seen that the responses attained through the geostatistical method have lower COVs than those from the non-stationary random field, which is due to consider the effect of the borehole location. It is also worth mentioning that since $\mathrm{COV}$ is invalid for parameters whose means are close to zero [62], the value of COV corresponding to the shear strain is not included in this comparison.

Table 8. Comparison of uncertainties in ground responses

\begin{tabular}{ccc}
\hline COV of Parameters (\%) & Non-stationary random field & Geostatistical method \\
\hline PGD & 35.02 & 21.96 \\
$\mathrm{~S}_{\mathrm{a}}$ & 17.36 & 12.26 \\
$\mathrm{~S}_{\mathrm{v}}$ & 18.11 & 11.88 \\
$\mathrm{~S}_{\mathrm{d}}$ & 17.67 & 12.59 \\
PGA & 14.29 & 8.33 \\
Amplification factor & 17.25 & 12.25 \\
\hline
\end{tabular}

\section{Conclusions}

Nonlinear time-domain ground response analysis implementing a stepwise integration procedure provides an accurate framework for simulation of the real nonlinear behavior of soil. On the other hand, seismic ground responses mainly depend on the soil's dynamic behavior, which is always associated with a significant degree of heterogeneity. In this paper, a new procedure for conducting stochastic nonlinear ground response analysis considering the existing boreholes' location on the soil parameters heterogeneity through the 
geostatistical method, i.e., Kriging estimation, was developed and applied to a real site. Initially, a program for deterministic nonlinear site response analysis in the time-domain was developed in MATLAB and then extended to stochastic analysis. The results of the deterministic analysis demonstrate acceptable agreement between the developed program and outputs from DEEPSOIL.

For the stochastic analysis, two different methods, including non-stationary random field and geostatistical estimation, were implemented to consider the spatial variability of soil parameters. The non-stationary random field model is based on depth-dependent trends obtained by nonlinear fitting of the average values of the boreholes' data. In contrast, the geostatistical method was based on Kriging estimation to apply the effect of the boreholes' location on the mean and standard deviation of the dynamic soil parameters. The obtained uncertainty of soil parameters at the construction location borehole location was used to generate random profiles through MCS. The stochastic seismic ground responses and the amplification factor were determined through both of the aforementioned methods. Some conclusions are summarized below:

- The results show that considering the effects of boreholes location can have a significant influence on seismic ground responses. In other words, the geostatistical method for prediction of the values of soil parameters at the construction location borehole may assign more weight to the boreholes which are closer to the target interpolation location. This procedure can lead to a more reasonable estimation of the uncertainties associated with soil parameters. In the site under study, the second borehole (i.e., BH.2) was the closest to the construction location; therefore, it had the greatest impact on the estimations. Additionally, since BH.2 has a relatively stiffer soil (in terms of more velocity and shear modulus) than those attained from the other two boreholes, the generated profiles through the geostatistical method are also stiffer than those from the non-stationary random field method. As a result, in the studied site, the use of the non-stationary random field method leads to larger PGD, shear strain, $S_{v}$, and $S_{d}$, while the geostatistical method provides larger surface accelerations, $\mathrm{S}_{\mathrm{a}}$, and amplification factor.

- According to the obtained shear strain, it can be concluded that in the studied site the profiles generated by the non-stationary random field method may experience higher shear strain values, which can be due to the fact that these profiles are softer compared to the generated profiles using the geostatistical method. Additionally, the highest shear strain is mobilized in the third layer (i.e., $5 \mathrm{~m}$ depth). The obtained standard deviation of the extremum shear strain from the non-stationary random field method at all depths is greater than the corresponding value for the geostatistical method.

- Based on the stochastic PGA assessment, it can be concluded that variations of the ground surface PGA from both methods have nearly normal distributions.

- The results indicate that the peaks of the stochastic amplification factors occur at periods around $0.6 \mathrm{sec}$ and $0.4 \mathrm{sec}$ for the non-stationary random field method and geostatistical method, respectively. This also demonstrates that the amplification factor of the geostatistical method at periods less than $0.47 \mathrm{sec}$ is above that of the non-stationary random field and, after this point, the amplification factor of the non-stationary random field is higher.

- Considering the borehole location in the estimations performed through the geostatistical method causes the final results to be closer to the data recorded near the construction location. Accordingly, this leads to reduction of the obtained soil parameters' uncertainty through the 
1 geostatistical method when compared to the non-stationary random field method. The 2 reflection of the uncertainties in the input parameters to the seismic ground responses reveals 3 that surface responses through the geostatistical method have lower COV, and among the 4 different responses, PGD and PGA reflect the highest and lowest dispersions due to 5 uncertainties in soil properties. 


\section{References}

2 [1] Sun C-G, Chung C-K. Assessment of site effects of a shallow and wide basin using geotechnical information-based spatial characterization. Soil Dynam Earthquake Eng. 2008;28(12):1028-44.

[2] Schnabel P, Lysmer J, Seed H. SHAKE-A computer program for earthquake response analyses of 5 layered soils. User's manual, EERC-72, Berkeley, CA. 1972.

[3] Matasovic N, Vucetic M, editors. Seismic response of soil deposits composed of fully-saturated clay and sand layers. Proc First International Conference on Earthquake Geotechnical Eng; 1995. Lo Presti DC, Lai CG, Puci I. ONDA: Computer code for nonlinear seismic response analyses of soil deposits. Journal of geotechnical and geoenvironmental engineering. 2006;132(2):223-36.

[6] Asgari A, Bagheripour M. Earthquake response analysis of soil layers using HFTD approach. Soil

[7] Jishnu R, Naik S, Patra N, Malik J. Ground response analysis of Kanpur soil along Indo-Gangetic

[8] Garini E, Gazetas G, Ziotopoulou K. Inelastic soil amplification in three sites during the Tokachioki M JMA 8.0 earthquake. Soil Dynam Earthquake Eng. 2018.

[11] Yee E, Stewart JP, Tokimatsu K. Elastic and large-strain nonlinear seismic site response from

[12] Tsai C-C, Chen C-W. Comparison study of one-dimensional site response analysis methods. Earthquake Spectra. 2016;32(2):1075-95.

[14] Pyke RM. Nonlinear soil models for irregular cyclic loadings. Journal of Geotechnical and 
[15] Vucetic M. Normalized behavior of clay under irregular cyclic loading. Can Geotech J. 1990;27(1):29-46.

[16] Lee M, Finn W. Dynamic effective stress analysis of soil deposits with energy transmitting boundary including assessment of liquefaction: DESRA-2. Soil Mechanics Series no. 38, Vancouver. British Columbia. 1978.

[17] Constantopoulos IV, Roesset JM, Christian J, editors. A comparison of linear and exact nonlinear analysis of soil amplification. 5th WCEE; 1973.

[18] Ramberg W, Osgood WR. Description of stress-strain curves by three parameters. 1943.

[19] Joyner WB, Chen AT. Calculation of nonlinear ground response in earthquakes. Bull Seismol Soc Am. 1975;65(5):1315-36.

[20] Iwan WD, editor On a class of models for the yielding behavior of continuous and composite systems1967: ASME.

[21] Borja RI, Chao H-Y, Montáns FJ, Lin C-H. SSI effects on ground motion at Lotung LSST site. Journal of geotechnical and geoenvironmental engineering. 1999;125(9):760-70.

[22] Hashash YM, Park D. Non-linear one-dimensional seismic ground motion propagation in the Mississippi embayment. Eng Geol. 2001;62(1):185-206.

[23] Phillips C, Hashash YM. Damping formulation for nonlinear 1D site response analyses. Soil Dynam Earthquake Eng. 2009;29(7):1143-58.

[24] Assimaki D, Li W, Steidl J, Schmedes J. Quantifying nonlinearity susceptibility via site-response modeling uncertainty at three sites in the Los Angeles Basin. Bull Seismol Soc Am. 2008;98(5):2364-90.

[25] Kaklamanos J, Baise LG, Thompson EM, Dorfmann L. Comparison of 1D linear, equivalent-linear, and nonlinear site response models at six KiK-net validation sites. Soil Dynam Earthquake Eng. 2015;69(1):207-19.

[26] Angina A, Steri A, Stacul S, Presti DL. Free-field seismic response analysis: The Piazza dei Miracoli in Pisa case study. International Journal of Geotechnical Earthquake Engineering (IJGEE). 2018;9(1):1-21.

[27] Rahman M, Yeh C. Variability of seismic response of soils using stochastic finite element method. Soil Dynam Earthquake Eng. 1999;18(3):229-45.

[28] Wang S, Hao H. Effects of random variations of soil properties on site amplification of seismic ground motions. Soil Dynam Earthquake Eng. 2002;22(7):551-64.

[29] Rosenblueth E. Point estimates for probability moments. Proceedings of the National Academy of Sciences. 1975;72(10):3812-4. 
[30] Nour A, Slimani A, Laouami N, Afra H. Finite element model for the probabilistic seismic response of heterogeneous soil profile. Soil Dynam Earthquake Eng. 2003;23(5):331-48.

[31] Bazzurro P, Cornell CA. Ground-motion amplification in nonlinear soil sites with uncertain properties. Bull Seismol Soc Am. 2004;94(6):2090-109.

[32] Li X, Wang Z, Shen C. SUMDES: A nonlinear procedure for response analysis of horizontallylayered sites subjected to multi-directional earthquake loading. Department of Civil Engineering, University of California, Davis. 1992:86.

[33] Andrade JE, Borja RI. Quantifying sensitivity of local site response models to statistical variations in soil properties. Acta Geotech. 2006;1(1):3-14.

[34] Thompson EM, Baise LG, Kayen RE, Tanaka Y, Tanaka H. A geostatistical approach to mapping site response spectral amplifications. Eng Geol. 2010;114(3):330-42.

[35] Rota M, Lai C, Strobbia C. Stochastic 1D site response analysis at a site in central Italy. Soil Dynam Earthquake Eng. 2011;31(4):626-39.

[36] Johari A, Momeni M. Stochastic analysis of ground response using non-recursive algorithm. Soil Dynam Earthquake Eng. 2015;69(1):57-82.

[37] Berkane HD, Harichane Z, Çelebi E, Elachachi SM. Site dependent and spatially varying response spectra. Earthquake Engineering and Engineering Vibration. 2019;18(3):497-509.

[38] Johari A, Vali B, Golkarfard H. System reliability analysis of ground response based on peak ground acceleration considering soil layers cross-correlation. Soil Dynam Earthquake Eng. 2020:xx-xx.

[39] Newmark NM. A method of computation for structural dynamics. Journal of the engineering mechanics division. 1959;85(3):67-94.

[40] Wilson EL. A computer program for the dynamic stress analysis of underground structures. CALIFORNIA UNIV BERKELEY STRUCTURAL ENGINEERING LAB; 1968.

[41] Rayleigh J, Lindsay R. The theory of Sound. Dover1945.

[42] Stewart JP, Kwok A0. Nonlinear seismic ground response analysis: Code usage protocols and verification against vertical array data. Geotechnical earthquake engineering and soil dynamics IV2008. p. 1-24.

[43] Vucetic M, Dobry R. Effect of soil plasticity on cyclic response. J Geotech Eng. 1991;117(1):89107.

[44] Darendeli MB. Development of a new family of normalized modulus reduction and material damping curves. 2001. 
[45] Menq F. Dynamic properties of sandy and gravelly soils [Ph. D. dissertation]. Austin: University of Texas. 2003.

[46] Kishida T, Boulanger RW, Abrahamson NA, Wehling TM, Driller MW. Regression models for dynamic properties of highly organic soils. Journal of geotechnical and geoenvironmental engineering. 2009;135(4):533-43.

[47] Yang L, Woods RD. Shear stiffness modeling of cemented clay. Can Geotech J. 2014;52(2):156-66.

[48] Kondner RL, Zelasko JS, editors. A hyperbolic stressstrain formulation for sands. Proc 2nd PanAmerican Conf on SMFE; 1963.

[49] Hardin BO, Drnevich VP. Shear modulus and damping in soils: design equations and curves. Journal of Soil Mechanics \& Foundations Div. 1972;98(sm7).

[50] Chopra A. K, 1995 Dynamics of Structures Theory and Application to Earthquake Engineering. University of California, New Jersey.

[51] Johari A, Amjadi A. Stochastic Analysis of Settlement Rate in Unsaturated Soils. Geo-Risk2017. p. 631-9.

[52] Johari A, Kalantari A. System reliability analysis of soldier-piled excavation in unsaturated soil by combining random finite element and sequential compounding methods. Bull Eng Geol Environ. 2021;80(3):2485-507.

[53] Li D-Q, Qi X-H, Phoon K-K, Zhang L-M, Zhou C-B. Effect of spatially variable shear strength parameters with linearly increasing mean trend on reliability of infinite slopes. Structural safety. 2014;49:45-55.

[54] Phoon K-K, Kulhawy FH. Characterization of geotechnical variability. Can Geotech J. 1999;36(4):612-24.

[55] Johari A, Gholampour A. A practical approach for reliability analysis of unsaturated slope by conditional random finite element method. Computers and Geotechnics. 2018;102:79-91.

[56] Boore DM. Effect of baseline corrections on displacements and response spectra for several recordings of the 1999 Chi-Chi, Taiwan, earthquake. Bull Seismol Soc Am. 2001;91(5):1199-211.

[57] Stokoe K, Darendeli M, Andrus R, Brown L, editors. Dynamic soil properties: laboratory, field and correlation studies. Earthquake geotechnical engineering; 1999.

[58] Johari A, Javadi A, Makiabadi M, Khodaparast A. Reliability assessment of liquefaction potential using the jointly distributed random variables method. Soil Dynam Earthquake Eng. 2012;38(1):81-7.

[59] Arnold C. Designing for Earthquakes: A Manual for Architects. Earthquake Engineering Research Institute, Oakland, California Available as a book or online from http://www fema gov/library/viewRecord do. 2007. 
[60] Idriss I. Earthquake ground motions at soft soil sites. 1991.

2 [61] Suetomi I, Yoshida N. Nonlinear behavior of surface deposit during the 1995 Hyogoken-Nambu earthquake. Soils and Foundations. 1998;38:11-22.

[62] Busing FM, Groenen PJ, Heiser WJ. Avoiding degeneracy in multidimensional unfolding by penalizing on the coefficient of variation. psychometrika. 2005;70(1):71-98.

[63] Fenton GA, Griffiths D. Risk Assessment in Geotechnical Engineering.

\section{Appendix}

In this section, the procedure of soil properties prediction at the construction location (hypotetical borehole) through the Kriging method is explained. The basic idea of Kriging is to estimate $\mathrm{X}(\tilde{\mathrm{X}})$ at any point using a weighted linear combination of the values of $\mathrm{X}$ at each observation point. Suppose that $\mathrm{X}_{1}, \mathrm{X}_{2}, \ldots, \mathrm{X}_{n}$ are observations of the random field, $\mathrm{X}(\tilde{\mathrm{X}})$, at the points $\tilde{\mathrm{x}}_{1}, \tilde{\mathrm{x}}_{2}, \tilde{\mathrm{x}}_{3}, \ldots, \tilde{\mathrm{x}}_{n}$ [63]. At the first step, a correlation function (e.g., exponentially decaying correlation) should be selected as follows:

$\rho=\exp \left\{-\frac{2\left|\tau_{i j}\right|}{\theta}\right\}$

15

16

17

18

19

20

21

22

where $\tau_{i j}$ is the separation distance between sample points $\left(\tau_{i j}=\left|\tilde{x}_{j}-\tilde{x}_{i}\right|\right)$, and as mentioned previously, the parameter $\theta$ is called the scale of fluctuation. In the selected site with the considered scale of fluctuation of $45 \mathrm{~m}$, the $\rho$ matrix was calculated as:

$\rho=\left[\begin{array}{lll}1.0000 & 0.2059 & 0.1390 \\ 0.2059 & 1.0000 & 0.3517 \\ 0.1390 & 0.3517 & 1.0000\end{array}\right]$

The covariance matrix associated with PI between sample points is just $C_{P I}=\sigma_{P I}^{2} \rho$ and since the variance of PI at the first layer is 0.7731 the $C_{P I}$ will be:

$C_{P I}=\left[\begin{array}{lll}0.7731 & 0.1592 & 0.1074 \\ 0.1592 & 0.7731 & 0.2719 \\ 0.1047 & 0.2719 & 0.7731\end{array}\right]$

Similarly, the covariance matrix associated with $\gamma$ and $V_{s}$ of the soil layers can be calculated. The Kriging matrix associated with PI at the first layer is then:

$K_{P I}=\left[\begin{array}{llll}0.7731 & 0.1592 & 0.1074 & 1.0000 \\ 0.1592 & 0.7731 & 0.2719 & 1.0000 \\ 0.1074 & 0.2719 & 0.7731 & 1.0000 \\ 1.0000 & 1.0000 & 1.0000 & 0.0000\end{array}\right]$

Placing the coordinate axis origin at the left bottom corner of the site gives the construction location coordinates $x=(33,15)$. Thus, the right-hand side vector $M$ is: 
$M=\left[\begin{array}{c}\sigma_{P I}^{2} \rho\left(\mathscr{Q}_{1}, x\right) \\ \sigma_{P I}^{2} \rho\left(\mathscr{X}_{2}, x\right) \\ \sigma_{P I}^{2} \rho\left(\mathbb{X}_{3}, x\right) \\ 1\end{array}\right]=\left[\begin{array}{l}0.2649 \\ 0.4439 \\ 0.2677 \\ 1.0000\end{array}\right]$

1

2 (ignoring the Lagrange parameter):

$\beta=\left[\begin{array}{l}0.2817 \\ 0.5203 \\ 0.1979\end{array}\right]$

Since the correlation matrix is unique for PI, $\gamma$, and $V_{s}$, the weights will be identical for

4 them. Thus the best estimates at the construction location for the first layer are:

$$
\left\{\begin{array}{l}
P I=(0.2817)(6.30)+(0.5203)(7.85)+(0.1979)(6.36)=7.12 \% \\
\gamma=(0.2817)(17.02)+(0.5203)(17.31)+(0.1979)(17.19)=17.20 \mathrm{kN} / \mathrm{m}^{3} \\
V_{s}=(0.2817)(161.2)+(0.5203)(184.7)+(0.1979)(157.2)=172.6 \mathrm{~m} / \mathrm{s}^{2}
\end{array}\right.
$$

5 The following equation can determine the estimation of variances:

$$
\sigma_{E}^{2}=\sigma_{x}^{2}\left(1+\beta^{T}\left(\rho \beta-2 \rho_{x}\right)\right.
$$

6 where $\rho_{x}$ is the vector of correlation coefficients between the samples and the the construction

7 location. For the Kriging weights and given correlation structure, this yields:

$$
\sigma_{E}^{2}=\sigma_{x}^{2}(0.6099)
$$

8 which gives the following individual estimation of standard deviations for the first layer:

$$
\left\{\begin{array}{l}
\sigma_{P I}^{2}=(0.7731)(0.6099)=0.4715 \rightarrow \sigma_{P I}=0.69 \% \\
\sigma_{\gamma}^{2}=(0.0212)(0.6099)=0.0129 \rightarrow \sigma_{\gamma}=0.11 \mathrm{kN} / \mathrm{m}^{3} \\
\sigma_{V_{s}}^{2}=(220.88)(0.6099)=134.72 \rightarrow \sigma_{V_{s}}=11.61 \mathrm{~m} / \mathrm{s}^{2}
\end{array}\right.
$$

9

This procedure is repeated to estimate soil properties for all layers.

10

11

12

13

14

15

16 